Running head: Rethinking Graduate Admissions

\title{
Bias, Fairness, and Validity in Graduate Admissions: A Psychometric Perspective
}

\author{
Sang Eun Woo ${ }^{1}$, James M. LeBreton ${ }^{2}$, Melissa G. Keith ${ }^{3}$, Louis Tay ${ }^{1}$ \\ ${ }^{1}$ Purdue University, ${ }^{2}$ Pennsylvania State University, ${ }^{3}$ Bowling Green State University
}

Accepted at Perspectives on Psychological Science

Last updated on October 6, 2021

Author Note.

Correspondence concerning this article should be addressed to Sang Eun Woo, Department of Psychological Sciences, Purdue University, 703 Third Street, West Lafayette, IN 47907. Email: sewoo@purdue.edu.

We thank Tara Behrend, Brent Bridgeman, Brian Connelly, Eric Drogin, Scott Highhouse, Kisha Jones, Deborah Rupp and her George Mason University colleagues, Rachel Saef and her Northern Illinois University colleagues, Terry Tracey, Bill Watson, and Purdue I-O Psychology Group for their helpful comments on earlier versions of the manuscript. We also thank Nathan Kuncel and three other (anonymous) reviewers for Perspectives on Psychological Science, as well as Dr. Matthew Rhodes who served as Action Editor for the manuscript. 


\begin{abstract}
As many schools and departments are considering the removal of the Graduate Record Examination (GRE) from their graduate admission processes to enhance equity and diversity in higher education, controversies arise. From a psychometric perspective, we see a critical need for clarifying the meanings of measurement bias and fairness, in order to create common ground for constructive discussions within the field of psychology, higher education, and beyond. We critically evaluate six major sources of information that are widely used to help inform graduate admissions decisions: grade point average, personal statements, resumes/CVs, letters of recommendation, interviews, and GRE. We review empirical research evidence available to date on the validity, bias, and fairness issues associated with each of these admission measures and identify potential issues that have been overlooked in the literature. We conclude by suggesting several directions for practical steps to improve the current admissions decisions, as well as highlighting areas in which future research would be beneficial.
\end{abstract}

Keywords: graduate admissions, validity, test, bias, fairness, discrimination, higher education 


\section{Bias, Fairness, and Validity in Graduate Admissions: A Psychometric Perspective}

Many psychologists in higher education are deeply concerned about issues of equity and equal opportunities (e.g., Hu, 2020). Over the years, significant concerns have been raised about the Graduate Record Examination (GRE) due to substantial score disparities, which are viewed by many as a systematic barrier to higher education for underrepresented minorities (URMs), such as Black, Hispanic, and low-income and/or first-generation students (Bleske-Rechek \& Browne, 2014; ETS, 2012; Pennock-Román, 1993). These are legitimate and important concerns to address, as relying heavily on GRE scores as the basis for admission to graduate training programs may result in limited diversity in academia. Conversations around the removal of GREs from the graduate admission process started more than a decade ago (Jaschik, 2008, 2019b; Tyson, 2014) and have materialized and intensified in several major institutions in the U.S. over the past few years. Emerging from the shadow of the COVID global pandemic, the unprecedented challenges associated with remote testing and economic hardship seem to be disproportionately affecting URM students (Hu, 2020). As such, many schools and departments are either implementing or exploring the possibility of moving away from GRE requirements as part of their admission processes, at least in the short term.

Advocates for suspending (or eliminating) the use of GRE test scores believe that doing so will engender a more diversified and larger applicant pool, thus facilitating the diversification of graduate training programs (especially for URM students). We fully recognize and endorse the importance of diverse representations and the ultimate goal of enhancing equity, diversity, and inclusion in higher education. However, we question whether eliminating the GRE will indeed lead to such outcomes. Apart from whether removing GREs will enhance diversity, some empirical studies (outside of the psychology discipline) have suggested that the GRE is not a 
strong predictor of graduate school success in those domains and thus should not be considered the gold standard for graduate school selection (e.g., Petersen et al., 2018). Such a claim needs to be carefully evaluated for its scientific rigor and generalizability, as it contradicts a large body of scientific evidence on the predictive validity of cognitive tests and thus, has significant implications for graduate schools' decisions over whether or not to include tests such as the GRE in their admission process.

The purpose of this article is not to "defend" the inclusion of GREs in graduate admissions. Instead, our central goal is to start an open and forward-looking discussion about how the validity and integrity of graduate admission decisions can be improved while also enhancing the diversity of those admitted to graduate programs. To achieve this goal, we examine the most commonly used assessments in the graduate admissions process - including but also going beyond the GREs. Specifically, we review whether (and to what extent) each of these assessments themselves may be subject to issues of bias and fairness; we also review the criterion-related validity evidence (if available). Policymakers and researchers alike are not immune to the effects of a focusing illusion, whereby one erroneously assumes that only the GREs are flawed. Early work seeking to address disparities and discrimination in the recruitment, admission, and retention of minority graduate students has identified problems with multiple sources of bias and discrimination associated with subjective evaluations (e.g., Pruitt \& Isaac, 1985), which should be carefully considered and investigated, especially given the highly subjective and unstructured nature of many of the assessment methods used in tandem with GREs (e.g., personal statements, letters of recommendation, quality/quantity of research experience). To this end, the current article clarifies the concepts of bias, fairness, and validity. It then uses these concepts to evaluate six of the most common assessments used to guide graduate 
admissions decisions: GRE, undergraduate grade point average [UGPA], personal statements, resumes/CVs, letters of recommendation, and interviews.

In the following, we start with a clarification of measurement-related concepts pertaining to bias and fairness, drawing from multiple authoritative articles on the matter, including the Standards for Educational and Psychological Testing (or Standards; American Educational Research Association [AERA], American Psychological Association, \& National Council on Measurement in Education, 2014), and Principles for the Validation and Use of Personnel Selection Procedures (or Principles; Society for Industrial and Organizational Psychology [SIOP], 2018) (Part 1). We see a critical need for clarifying the meanings of validity, bias, and fairness in order to create common ground for constructive discussions within the field of psychology, higher education, and beyond. Next, we review empirical research evidence available to date on the validity, bias, and fairness issues associated with each of the six admission measures and identify potential issues that have been overlooked in the literature (Part 2). We conclude by suggesting practical steps that can be taken to improve the current admissions decisions and highlight areas in which future research would be beneficial (Part 3).

\section{PART 1: CLARIFYING CONCEPTS}

\section{Test vs. Assessment}

The term "test" refers to any "device or procedure in which a sample of an examinee's behavior in a specified domain is obtained and subsequently evaluated and scored using a standardized process" (p. 2; Standards, AERA et al., 2014). Tests may be described both in terms of "what they are designed to measure (e.g., content/constructs) or how they measure what they are designed to measure (e.g., methods)" (p. 2). On the other hand, the term "assessment" broadly refers to a "process that integrates test information with information from other sources 
(e.g., information from other tests, inventories, and interviews; or the individual's social, educational, employment, health, or psychological history)" (p. 2). Thus, for the purpose of our review, the term test will strictly refer to GRE, which is the only assessment method that uses a standardized process. In contrast, the term assessment will be used more inclusively, referring to all six aforementioned sources of information gathered during the graduate admissions process, as well as how these sources are utilized to evaluate the candidates.

The term "measurement" may be defined as "assigning symbols to objects so as to (1) represent quantities of attributes numerically (scaling) or (2) define whether the objects fall in the same or different categories with respect to a given attribute (classification)" (p. 3; Nunnally \& Bernstein, 1994). A “measure" is a tool used for measurement - for example, GRE Verbal Reasoning is a measure of "the ability to analyze and draw conclusions from discourse, reason from incomplete data, [...], and understand relationships among words and among concepts." (ETS, n.d.-a).

\section{Selection}

A method of measurement, testing, and assessment is distinguished from a method of selection. Graduate admission decisions can be made in a number of different ways. These selection methods vary in terms of how multiple sources of information (e.g., GRE, resume/CV, interviews) are used to derive a final decision. There are various approaches to combining applicant data, which can be summarized into two broad types: mechanical (i.e., algorithmic) and clinical (i.e., holistic) approaches. The former involves using a formula to aggregate multiple scores associated with each applicant into a composite. In contrast, the latter involves group consensus meetings where individual committee members' opinions (either numeric or 
qualitative) are 'holistically' discussed and integrated using collective judgment, insight, and intuition (Kuncel et al., 2013).

One possible graduate admission scenario (as an example) is as follows: First, the admissions committee in a graduate program reviews all applications submitted and entered into the database. Second, the committee rank-orders the candidates based on a combination of numeric scores such as GREs and UGPA (depending on the emphasis of the program, specific scores such as GRE-Quantitative or GRE-Verbal Reasoning may be given more weight in the score aggregation). Third, the committee takes a closer look at the top $25-50 \%$ of the candidates by reviewing other application materials more closely (e.g., statement of purpose, resume/CV, letters of recommendation). In addition to the composite scores, special attention is often given to those who have been introduced via a mutual contact (e.g., the candidate's research advisor). Many graduate programs also conduct in-person or phone interviews with those who make the shortlist. Fourth, when all relevant information on the candidates has been collected, the committee decides who should be given an admission offer. Such decisions are often made using a clinical method (through a group consensus after discussing each candidate's strengths and weaknesses) rather than an algorithmic (statistical) method.

\section{Predictors vs. Criteria}

The term criteria will be used in a manner consistent with the Standards (AERA et al., 2014) to refer to context-relevant outcomes or behaviors that are "...operationally distinct from the test” (p. 17). Specifically, we define criteria as academically-relevant behaviors and outcomes of typical interest to educational institutions, including (but is not limited to): graduate grade point average (GGPA), graduation rates, publications, conference presentations, teaching 
evaluations, annual performance evaluations, qualifying/comprehensive exams, and theses/dissertations. We use $Y$ to denote criteria.

What educators often refer to as 'graduate admission criteria' or 'evaluation criteria' are, in fact, predictors (or the "X" variable) of important graduate school outcomes (i.e., criteria, or the "Y" variables as noted above). Predictors can be described as either (a) observed measures i.e., methods of assessing constructs that are known (or claimed) to be predictive of the criteria of interest (e.g., letters of recommendation; personal statements), or (b) the constructs themselves (e.g., perseverance; verbal fluency). The former includes operational concerns associated with observed data (e.g., errors or reliability of the assessment method; design considerations such as range restriction or use of convenience samples), whereas the latter focuses on the theory itself independent of measurement and design issues. Figure 1 illustrates a conceptual example of graduate admissions predictors and criteria, delineating measures (in boxes) and constructs (in circles).

\section{Criterion-Related Validity Evidence}

Measurement validity is a unitary concept, which refers to the extent to which evidence supports inferences drawn from test scores (Standards, AERA et al., 2014) ${ }^{1}$. There are many ways in which a measure's validity is evaluated and established, and one of the major types of validity evidence is called criterion-related validity evidence. It refers to the (accumulated) data that are used to support inferences linking scores on a predictor measure with scores on a criterion measure (AERA et al., 2014; Binning \& Barrett, 1989; Landy, 1986; Messick, 1995; SIOP, 2018). Such linkage typically takes the form of bivariate correlation coefficients, $r_{Y X}$, or unstandardized regression coefficients obtained by regressing $Y$ onto $X, b_{Y X}$.

\footnotetext{
${ }^{1}$ Tests themselves are neither valid nor invalid, rather it is the inferences drawn from test scores that are judged to render valid or invalid inferences (Binning \& Barrett, 1989; Sireci, 2016; cf., Borsboom et al., 2004).
} 


\section{Measurement Bias}

Psychometrically, measurement bias occurs when a test or assessment produces different scores between subgroups who have the same level of ability at the time of measurement (Drasgow, 1984, 1987). In other words, bias exists when belonging to a specific subgroup results in systematically lower or higher scores, controlling for the actual ability that is being measured. Another way of viewing measurement bias is that a measure systematically includes constructirrelevant variance (e.g., race, gender, age). Indeed, most experts agree that measurement bias may be defined as systematic variance in scores, which would differentially affect the performance of test-takers who belong to different groups (Standards, AERA et al., 2014; Principles, SIOP, 2018).

As illustrated in Figure 2, measurement bias can occur due to the systematic omission of construct-relevant content (i.e., deficiency) or the systematic inclusion of construct-irrelevant content (i.e., contamination) (Messick, 1995). Developers of the GRE and other high-stakes tests go through a series of quality control efforts that are based on substance (cultural sensitivity review of content) and statistics (psychometric analysis of items). This helps to eliminate problematic items before they are formally added to item banks (e.g., see Wendler \& Bridgeman, 2014). On the other hand, the sources of construct-irrelevant variance may be particularly problematic when such variance is derived from systematic sociocognitive biases that negatively impact URM students.

Table 1 contains a general summary of potential sources of construct-irrelevant variance (i.e., measurement bias) associated with the six most commonly used assessment methods in graduate admissions. At this juncture, it is critical to note that not all assessment methods included in this review are qualified as proper "measurements" in many real-life cases. Many 
graduate programs do not assign symbols (i.e., classify) or numeric scores (i.e., scale) to individuals when using these assessments in their admissions process, which makes it impossible to evaluate the presence and magnitude of potential measurement biases and also opens up universities to increased legal scrutiny. We revisit this point in the later parts of the paper. For now, we proceed to use the terms measures and measurements with the understanding that measurements may happen either formally (i.e., assigning actual symbols or numbers to each individual) or informally (i.e., qualitative and subjective differentiation among individuals on a given attribute; e.g., 'Steve has a stronger personal statement that Mary').

As noted in Table 1, all six assessments reviewed here could be impacted by content contamination or deficiency due to inappropriate sampling of content from the construct domain. Furthermore, those measures that rely on subjective human judgments are further susceptible to a wide array of well-known sociocognitive biases and rater biases. Beyond the matter of implicit biases that are believed to be embedded in almost all subjective evaluations, a few illustrative examples include:

1. Mere-exposure effect: Greater exposure to some stimulus (e.g., students of a particular race or gender) may result in increased liking for the stimulus (Zajonc, 1968).

2. Truth effect: Statements that have been repeated (e.g., stereotypic beliefs about race or gender) are judged to be "true" with a greater degree of confidence than new or novel statements (Hasher et al., 1977; Schwartz, 1982).

3. Confirmation bias: Differentially seeking or weighting information that is consistent with (or favorable to) one's beliefs, assumptions, or predictions (Nickerson, 1998). 
4. Halo bias: The tendency to assign similar scores to different components of performance even when those components or dimensions are known to be distinct (Nisbett \& Wilson, 1977).

5. Leniency/severity biases: The tendency for a rater (e.g., faculty member writing a letter of recommendation) to systematically inflate or deflate the scores assigned to a set of stimuli (e.g., his or her undergraduate research assistants) (Hoyt, 2000).

6. Similar-to-me bias: The tendency to be more attracted to others (e.g., undergraduates applying to work as a research assistant; students applying to graduate programs) when they share characteristics similar to the self (e.g., similar race or gender; attended the same university) (Milkman et al., 2015).

In contrast to the GRE, which is an objectively scored and standardized test, all of the remaining assessment methods used to inform graduate admissions decisions are based, either directly or indirectly, on the subjective evaluations of others. Consequently, these measures are at the risk of being influenced by the aforementioned (and many more) sociocognitive and rater biases. Moreover, non-standardized testing practices suffer from issues of unreliability in general - allowing more sources of construct-irrelevant variance (both error and systematic) into the measurement. In addition, biases may arise when admission decisions are made using a holistic approach (Highhouse \& Kostek, 2013; Jones \& Roelofsma, 2000; Stasser \& Titus, 1985). The consequence of not carefully addressing these biases is that it can lead to continued disparities (Dovidio \& Fiske, 2012), as well as compromised predictive validity by introducing irrelevant sources of variance ${ }^{2}$ Importantly, although many of these biases have large literatures supporting

\footnotetext{
${ }^{2}$ In many audit studies examining discrimination in employment, it has been shown that gendered or URM names on resumes can subjectively bias interview call-backs (Bertrand \& Mullainathan, 2004), which occurs in both small and large organizations (Banerjee et al., 2018). According to a meta-analytic review (Quillian et al., 2017), this type of hiring discrimination does not seem to be reducing even since 1989. This issue likely generalizes to the graduate
} 
their existence, there is limited programmatic research evaluating the presence and magnitude of these biases within the specific context of selecting students into graduate programs (see our discussions in Part 2 and Part 3).

\section{Fairness}

The term fairness is best viewed as a psycho-social concept that is inherently anchored in values and beliefs, both at the individual and societal levels. After a deliberate process of studying the various origins of the fairness concept, it has been concluded that fairness lacks a consensus definition and "is used in many different ways in public discourse" (p. 49, Standards, AERA et al., 2014; also see Principles, SIOP, 2018). That said, the contemporary psychometric perspective (e.g., Standards [AERA et al., 2014] and Principles [SIOP, 2018]) emphasizes the importance of (a) equitable treatment during the testing/assessment process (e.g., access to practice materials, access to the technology needed to complete tests/assessment, use of standardized instructions and consistent time limits, reasonable accommodations for individuals with documented disabilities); (b) the absence of measurement bias; (c) the absence of predictive bias (e.g., when the use of a common regression line does not result in underprediction of performance for minority group members; Berry, 2015; Cleary, 1968); and (d) accessibility to the underlying focal constructs assessed (e.g., demographic characteristics should not restrict the measurement of the focal construct).

Aside from the psychometric requirements for fairness, all six sources of information used in graduate admissions suffer from considerable challenges with a broader concept of

admissions context where faculty can similarly exhibit similar types of discriminatory behaviors based on resumes. Even in graduate school, students experience discrimination and harassment (Williams \& Writer, 2019). Educators themselves (who eventually provide recommendations) are often found to be implicitly biased against URM students (Chin et al., 2020). Indeed, research shows that implicit bias exists in letters of recommendation (Houser \& Lemmons, 2018a). Moreover, receivers of honest recommendations believe more physically attractive candidates to likely to be more successful (Nicklin \& Roch, 2008). 
(societal) fairness. Here we highlight two interrelated problems: (a) disproportionate improvement opportunities on each of the six assessments included in graduate admissions decisions (e.g., costs associated with taking and studying for GRE, attending a prestigious college, foregoing employment opportunities to gain relevant research experience or mentorship) and (b) mean-level differences between groups on the predictors of interest. In many situations, the former is causally linked to the latter, in that when a particular group has limited access to improving one's performance on the predictor measures, it is inferred to be the cause of group mean differences on those predictor measures. We further elaborate on these points in Part 2.

Relatedly, the concept of discrimination has also been defined in a number of different ways, which spans social, moral, and practical dimensions (Colella et al., 2017). From a legal perspective, a claim can be made that a graduate admission system (or the use of a particular test in the system) is discriminatory. Taking race as an example, within the employment context (e.g., selecting a student to work as an RA or TA), below is a direct quote from the U.S. Equal Employment Opportunity Commission (EEOC) website (EEOC, n.d.):

Race discrimination involves treating someone (an applicant or employee) unfavorably because he/she is of a certain race or because of personal characteristics associated with race (such as hair texture, skin color, or certain facial features). Color discrimination involves treating someone unfavorably because of skin color complexion.

Importantly, for such a claim to stand in court, a great deal of data are required to establish (a) the relevance of the content comprising the assessment, (b) criterion-related validity evidence, (c) evidence for potential measurement bias, and (d) evidence for potential predictive bias. In a public discourse around assessments and selections in higher education, however, the GRE tests (along with other standardized admissions tests such as SAT and ACT) are often criticized as 'discriminatory' absent such evidence. Instead, these criticisms are made based on the racial disparities in the test scores or the resulting selection outcomes that reveal (and appear to 
perpetuate) disparities. Most certainly, the problem of discrimination can (and should) be examined not only from a legal perspective but also from many other perspectives (e.g., history, sociology, psychology, philosophy, politics).

However, we find the logic behind such criticisms to be both misleading and potentially harmful (NCME.org, 2019; Snyder, 2020). Criticizing the tests themselves as discriminatory and responsible for racial inequities in graduate (or college) admissions is much akin to "blaming a thermometer for global warming" (NCME.org, 2019). It is also analogous to calling COVID medical tests discriminatory because "there is evidence that some racial and ethnic minority groups are being disproportionately affected by COVID-19" (CDC, 2020), rather than suggesting that the mean differences in COVID rates across racial and ethnic groups are reflecting underlying systemic issues. Focusing on the metric that seeks to accurately reflect the reality without solving the underlying causal variables engendering those real group differences is not only misleading but potentially harmful for the goals of driving most graduate admission decisions: enhancing both the diversity and excellence of candidates accepted into graduate training programs (also see Snyder, 2020).

We would like to be very clear. Subgroup differences in the test score are real, and they can lead to adverse impact - i.e., when the use of a common selection standard results in the exclusion of a legally protected subgroup (e.g., categories based on sex, race, color, national origin, disability status) at a significantly higher rate than another subgroup (e.g., White students). This reality indeed signals significant challenges for establishing greater social justice. We wholeheartedly join the public outcry and the numerous community-based, institutional, and policy-level efforts toward creating greater racial equity (i.e., equal opportunities for all), which is now being culminated into the worldwide anti-racism movement in the year 2020 onward 
(e.g., George Floyd and Black Lives Matter). For this very reason, it is critical to discern where the real problem of discrimination and inequalities in higher education lies. Specifically, where in the process of graduate school admission decisions are bias and fairness issues most likely to arise? Is the GRE the real culprit, or have we overlooked other more significant sources of bias and unfairness? What are the likely consequences of eliminating the GRE from all graduate admission decisions? Specifically, would eliminating the GRE result in decisions that are free from bias and unfairness? How will it affect the validity of graduate admission decisions? Would sole reliance on subjective assessments of graduate students potentially increase the legal liability of colleges and universities? We address these questions in the following section.

\section{PART 2: CRITICALLY EVALUATING ALTERNATIVES TO GRE}

Using the key concepts outlined in Part 1, we now delve into a more critical and detailed analysis of the six major sources of information used in graduate admissions: UGPA, personal statements, resumes/CVs, letters of recommendation, interviews, and the GRE. The goal here is to provide a review of empirical research on bias, fairness, and validity issues related to each of these assessment methods while highlighting specific areas in which more careful research attention is needed. In evaluating validity evidence in the existing literature, we used the following effect size benchmarks as derived from Bosco et al.'s (2015) study of classifying 147,328 correlational effect sizes published in two major industrial-organizational psychology journals between 1980 and 2010: $r$ less than .09 is considered small (weak), .09 to .26 medium (moderate), and > .26 large (strong) $)^{3}$.

\footnotetext{
${ }^{3}$ Bosco et al. (2015) also provide more context-specific effect size benchmarks. For predicting performance from all knowledge, skills, and abilities $(k=1,385), .13$ and .31 were the demarcations of small vs. medium vs. large effects (i.e., .13 as the upper bound of small effects, and .31 as the lower bound of large effects); for predicting performance from all psychological characteristics $(k=3,135)$, such demarcations were .10 and .23 .
} 
We used three approaches to identify relevant literature during our search (see Appendix A for an overall flow diagram). First, we conducted a keyword search in all available databases for the combination of the following keywords: GRE, undergraduate GPA, undergraduate grade point average, personal statement, interview, college prestige, undergraduate prestige, university rank, university tier, research experience, letters of recommendation paired with graduate school, graduate admission, bias, subgroup differences, racial differences, gender differences, differential validity, differential prediction. This search yielded a total of 2041 potentially useful articles. Second, we identified 802 articles through Google Scholar that had cited Kuncel et al. (2001). Third, we identified 178 articles through an ancestry search of the following key articles: Kuncel et al. (2010), Kuncel et al. (2014), Murphy et al. (2009), and Sackett and Kuncel (2018). After removing the duplicate articles, 830 articles were screened for relevance to our topic and research questions. More specifically, articles were retained if they considered predictors of graduate student success, the validity of these predictors, bias, or fairness. During this process, 227 articles were retained for further consideration. After a closer examination of the remaining articles, 35 were removed because they were not relevant to our research questions or focused on success in a graduate program outside the scope of this manuscript (e.g., MBA, Dental School, Medical School). The remaining 192 articles were reviewed, and broad findings from this search are summarized below, as well as in Table 2.

\section{Undergraduate GPA}

In a large meta-analytic review, Kuncel et al. (2001) found that undergraduate GPA (or UGPA) was correlated with a number of relevant graduate school criteria. Specifically, UGPA had a sample weighted mean correlation of $.28(\rho=.30$, after correcting for range restriction and measurement error in the criterion) with graduate GPA (GGPA), a weighted mean correlation of 
$.30(\rho=.33)$ with first-year GGPA, a weighted mean correlation of $.12(\rho=.12)$ with comprehensive exam scores, and a weighted mean correlation of $.25(\rho=.35)$ with faculty ratings of graduate student performance. Similar to the results for the GRE, UGPA was not a particularly strong predictor of degree attainment $(r=.12)$ or time to completion $(r=-.08)$.

As with the GRE, UGPA is a cognitively loaded predictor, but it also may be influenced by various sociocognitive and rater biases when the grading is more subjective. Research on subgroup differences tends to find that women have higher UGPAs than men (Chapell et al., 2005; Cohn et al., 2004; Hughey, 1995; Khwaileh \& Zaza, 2011; M. J. Murphy et al., 1981; Sheard, 2009; Sonnert \& Fox, 2012; Voyer \& Voyer, 2015) and Black students have lower UGPAs than White students (Hughey, 1995; Roth \& Bobko, 2000). In a meta-analysis examining gender differences in scholastic achievement, Voyer and Voyer (2014) found that women had higher undergraduate grades compared to men $(d=.21)$; however, this difference was largest in language courses $(d=.21)$ and was much smaller for math courses $(d=.12)$ and became non-existent in science courses $(d=.01)$. These results for math and science appear to be moderated by factors such as sex composition of the course — when the course was majority men, no significant differences were found in these courses; however, when the course was majority women or had an equal representation of men and women, then the women tended to have higher course grades than the men $(d=.14$ to .32$)$. Concerning racial subgroup differences within college contexts, Roth and Bobko (2000) observed that subgroup differences followed an increasing linear trend - that is, they grew over the course of college. Whereas the Black-White cumulative GPA difference for college Sophomores was .21, the difference had increased to .78 for Seniors. It is the latter value that is most immediately relevant for our discussion of using UGPA as a source of information to inform graduate school admission decisions. 
These differences as a function of sex and race may stem from a number of different sources and are likely complex. For example, the Black-White difference may be due, in part, to racial differences in socioeconomic status and disparities in high school education (Fletcher \& Tienda, 2010). Compared to students of high socioeconomic status, low socioeconomic status students are more likely to be first-generation college students with varying levels of parental support and are more likely to have a job working longer hours, leaving less time for studying (Walpole, 2003). Indeed, Walpole (2003) reported that low SES students spent less time studying compared to high SES students. Socioeconomic status also impacts the high school one attends, which has also been shown to substantially contribute to the prediction of UGPAs (Betts \& Morell, 1999).

UGPA differences between men and women are often attributed to differences in the difficulty levels of courses selected and group differences in conscientiousness (Keiser et al., 2016). Keiser and colleagues (2016) examined differential prediction of ACT on UGPA and found that while course choice only explains a small amount of the underprediction of women's UGPAs, conscientiousness likely plays a larger role in differential prediction. Other research has found that attractive women may receive higher grades than men of comparable achievement levels (Murphy et al., 1981), suggesting that cognitive biases may influence grading, particularly when grading is more subjective. We did not find any studies that specifically tested the degree to which group mean differences in UGPA could be attributed to potential measurement bias.

\section{Personal Statements}

Most graduate admissions committees also consider personal statements in an attempt to gauge fit, writing ability, and other constructs that are more difficult (or impossible) to quantify or gauge using the GRE or UGPA (Walpole et al., 2002). The predictive validity for personal 
statements, however, is questionable. Based on a small number of studies $(k=8 \sim 10)$, Murphy and colleagues (2009) conducted a meta-analysis and found that ratings derived from personal statements were moderately correlated with GGPA $(r=.13)$ and with faculty performance ratings $(r=.09)$; however, they did not find support for their incremental validity over test scores and prior grades. Personal statements also suffer from a lack of construct validity evidence as well; Powers and Fowles (1997) found that personal statements are poor indicators of writing ability relative to standardized measures. Specifically, the authors argued that personal statements are often reviewed and heavily edited (often by multiple others), making it a questionable measure of one's individual writing ability.

With respect to bias, there is research to suggest that when writing, men use more agentic and self-promotional language compared to women (Babal et al., 2019; Osman et al., 2015). Although not directly examined, these and other differences may influence how these statements are evaluated by others. With respect to fairness, it is important to consider that some students have more resources, access to mentors, and so forth to help guide the crafting of effective personal statements. For example, minority, first-generation, or low socioeconomic status students may not have the social capital to seek such support. In addition, it is important to note that there is a vibrant market for people who can pay for someone to help with their personal statements for graduate school applications, which likely creates unequal opportunities for improving the quality of personal statements, disadvantaging those with less financial resources.

Taken together, personal statements appear to have limited validity evidence, appear to be vulnerable to an array of cognitive biases, and are likely to invoke concerns related to fairness issues due to differences in content and inequitable access to informational and supportive resources. Given this, research is needed to establish what constructs or attributes are most 
appropriately examined by personal statements (e.g., research match, degree of program interest, writing ability) and whether there is a way to standardize personal statements to better assess these attributes. Alternatively, the constructs we are attempting to measure may be better assessed with other instruments.

\section{Resumes/CVs}

Resumes or CVs are often used to assess research experience, as well as other credentials such as the prestige of the applicant's undergraduate institution. Miller et al.'s (2021) recent meta-analysis found that prior research experience (operationalized as amount of time spent on conducting research or working in a laboratory) did not predict graduate students' academic performance (i.e., GGPA, performance in individual classes, degree attainment, and faculty ratings $)(r=.01, \rho=.01,95 \% \mathrm{CI}[-.06, .08])$, degree attainment $(r=.05, \rho=.05,95 \% \mathrm{CI}[-.68$, $.77])$, professional performance $(r=.04, \rho=.06,95 \%$ CI $[-.27, .29])$, or publication performance $(r=.11, \rho=.11,95 \%$ CI [-.06, .29]). Perhaps more surprisingly, previous research experience was also unrelated to other predictors used in graduate admissions $(r=-.08$ to .08$)$. Notably, the small number of studies included in each analysis $(k=2$ to 8$)$ suggests that more research is needed on this topic.

Despite the lack of validity evidence, faculty view research experience as an important factor of consideration across a number of disciplines (Chari \& Potvin, 2019; Norcross et al., 2005; Pashak et al., 2012). Researchers also view research involvement as a valuable experience for undergraduate students (Lei \& Chuang, 2009). In particular, these experiences have been shown to increase self-reported interest in graduate education and research readiness (Harsh et al., 2012; Lopatto, 2007; Russell et al., 2007; Shaw et al., 2013). Research involvement is perceived to be particularly beneficial for women and underrepresented minorities and may be 
one key intervention to increase pipeline diversity (Coronado et al., 2012; K. A. Kim et al., 2011; Lopatto, 2007; O’Donnell et al., 2015; Russell et al., 2007). When evaluating applicants based on their prior research experiences, one must consider who has access to research experiences and whether barriers to getting involved in research are unequally distributed across different subgroups (Bangera \& Brownell, 2014; Y. K. Kim \& Sax, 2009). Past research has found that low SES students and high SES students are similarly likely to work with a faculty member doing research (Walpole, 2003); however, it is unclear how this might intersect with race or gender. Based on our review, this is an area of research that currently requires additional attention.

Much like research experience, it is unclear whether undergraduate institution prestige has a direct impact on graduate student success. With both measures, it is difficult to disentangle the impact of research participation and prestige of the undergraduate institution from both selfselection and selection. The limited available research does suggest that prestige or rank of the undergraduate institution is associated with higher research productivity and future earnings (Hersch, 2019; Kim \& Kim, 2017), and historically, social class and undergraduate rank were predictors of attending a highly ranked graduate school, though this may be evidence of bias rather than validity (Hersch, 2019; Lang, 1987).

Of course, not everyone can attend the highest-ranked universities and afford the price tag. The average cost of attending one of the U.S. News top 25 American Universities ranges from approximately $\$ 52-54 \mathrm{~K}$ per year. Notably, many students_-particularly those from disadvantaged backgrounds - may not pay the full "sticker price" due to scholarships; though, most elite schools tend to admit students from the highest SES (Aisch et al., 2017; Jaschik, 2019a; Larkin, 2018). It also appears that Black and Hispanic students remain somewhat 
underrepresented in elite universities ${ }^{4}$. Students from low socioeconomic backgrounds have also been found to enroll in less selective institutions, which may have fewer resources and access to research opportunities (Walpole, 2003).

\section{Letters of Recommendation}

Letters of recommendation are ubiquitous in graduate student admissions. According to a study that surveyed departmental representatives in psychology across multiple years (19712004), letters of recommendation have been rated as the most important piece of information in graduate admissions (Norcross et al., 2005). Letters can offer information about an applicant's noncognitive skills that may not be measured by standardized tests focusing on cognitive abilities (e.g., GRE). Indeed, ratings derived from letters of recommendation (either by the letter writer or by readers) showed weak to moderate correlations with standardized verbal and quantitative tests (.14 and .08 , respectively) and were correlated most strongly with personal statements (.41; Kuncel et al., 2014). Letters of recommendation also yield only minor incremental validity over the GRE and UGPA for predicting faculty performance ratings and Ph.D. attainment but are not related to GGPA (Kuncel et al., 2014). Despite the small incremental validity, Kuncel and colleagues (2014) view these results as promising for predicting persistence and motivation in graduate school, as these are often difficult constructs to measure.

\footnotetext{
${ }^{4}$ In 2016, the percentage of Black students enrolled in the top 25 American Universities ranged from 1.2\% to $10 \%$ $(M=5.1 \%)$. Likewise, the percentage of Hispanic students enrolled at these same universities ranged from $4.6 \%$ to $16.9 \%(M=8.5 \%)$; whereas Black students and Hispanic students between the ages of 18 and 24 comprised $14.6 \%$ and $21.7 \%$ of the population of the United States during that time, respectively (National Center for Education Statistics, 2017). As a reference point, however, White students between 18 and 24 comprised 54.3\% of the population in 2016, and their representation at the top 25 American Universities ranged widely from $29.8 \%$ to $64 \%$ $(M=42.86 \%)$. Asian students are perhaps the only racial subgroup who could not be considered underrepresented in the top 25 American universities; the representation of Asian students ranged from $4.7 \%$ to $26.9 \%(M=15.02 \%)$ despite making up 5.5\% of the population between 18 and 24 . While the reason for these enrollment patterns is unclear and likely complex, the underrepresentation may not be a result of discrimination. Examining socioeconomic status, Sackett et al. (2012) found that the SES composition of the applicant pool was similar to the SES composition of enrolled students suggesting that low representation of low-SES students is the result of lower application rates rather than exclusion by universities. Research is needed to examine such patterns with race and gender as well.
} 
Despite having some promise, letters of recommendation are plagued with a number of problems, including poor interrater reliability (Baxter et al., 1981) and the potential for gender or racial differences in letter content (Houser \& Lemmons, 2018b; Lin et al., 2019; Lunneborg \& Lillie, 1973; Madera et al., 2009, 2019; Morgan et al., 2013; Schmader et al., 2007). To our knowledge, research examining subgroup differences in letter content has not examined whether these differences translate into different selection outcomes in the context of graduate admissions; however, Madera et al. (2009, 2019) examined this question among applicants for a faculty position. This research found that women were described as more communal and less agentic than men and were more likely than men to receive what they termed "doubt raisers" (e.g., negativity, irrelevant information, weak praise, hedging). In turn, communal descriptions and certain doubt raisers negatively predicted hiring decisions. Another study found similar evidence of race and gender differences in the communal vs. agentic language used in recommendation letters for radiology residency programs (Grimm et al., 2020). Likewise, experimental research had found that even when participant readers knew that letters were inflated, those with inflated letters of recommendation were more likely to be hired (Nicklin \& Roch, 2008). This same research also found that letters of recommendation are biased by irrelevant factors such as gender and physical attractiveness. Thus, cognitive biases and subgroup differences in letter content certainly influence selection decisions; however, research is needed to understand how these factors influence graduate student admissions. With respect to fairness, we are not aware of research examining access to letters of recommendation by race, gender, socioeconomic status, or other factors. We suspect that subgroups (e.g., low SES students) who rely on off-campus work or work longer hours may have less time to develop relationships with faculty who could write an effective letter of recommendation (Terenzini et al., 2001). 
To address some of the main concerns surrounding bias in letters of recommendation, a number of researchers have suggested standardizing letters of recommendation (Houser \& Lemmons, 2018b; Kim \& Kyllonen, 2006; Kyllonen et al., 2005; Liu et al., 2009; Miller et al., 2019). Interestingly, this is not new, as psychologists have been decrying the lack of standardization in letters of recommendation since at least the 1960s (e.g., Holder, 1962). There is some limited support suggesting that standardizing letters of recommendation does reduce subgroup differences in admissions (Friedman et al., 2017), as does asking raters to elaborate on their ratings (Morgan et al., 2013). We concur that standardization may increase both the validity and reliability of the use of recommendation letters and should be examined in future research.

Once these assessments are standardized, researchers will be better able to evaluate these ratings for measurement bias.

\section{Interviews}

Interviews in graduate admissions typically take place after a program has narrowed down its list of applicants. That is, students who are invited for an interview have already passed previous hurdles (e.g., acceptable GRE scores, sufficient GPA, strong letters of recommendation). As a result, there is a dearth of research examining the extent to which these - often unstructured-interviews are effective for selecting graduate students ${ }^{5}$ (see Kuncel, Tran, \& Zhang, 2020 for a more detailed review). There is, however, a large body of research on interviews in the employment context conducted by organizational researchers. An exhaustive

\footnotetext{
${ }^{5}$ The extant research on interviews primarily examines outcomes in the medical school context. Goho and Blackman (2006) provided a meta-analysis of interviews for predicting academic success (i.e., GPA, exam scores, attrition rates, completion rates, awards) and clinical success in the medical context and found a small positive relationship between interview scores and academic success $(r=.06,95 \% \mathrm{CI}[.03, .08])$ and a moderate positive relationship between interview scores and clinical success $(r=.17,95 \% \mathrm{CI}[.11, .22])$. Other research has found that multiple mini-interview scores do not differ between underrepresented in medicine groups and majority groups, possibly due to the structured nature of these interviews (Gale et al., 2016; Henderson et al., 2018; Lumb et al., 2010; Terregino et al., 2015).
} 
review of this research is outside the scope of the present manuscript and has been reviewed elsewhere (e.g., Macan, 2009); however, we do provide a brief overview of this research in Table 2, given the lack of relevant research available in the context of graduate admissions.

From this literature, a clear picture emerges - increasing structure in interviews (e.g., through standardization in the questions asked and/or the scoring protocols used to evaluate interviewees' answers) increases the validity and reliability of interviews (Barrick et al., 2009; Campion et al., 1997; Chapman \& Zweig, 2005; Conway et al., 1995; Cortina et al., 2000; Huffcutt \& Arthur, 1994; Macan, 2009; Melchers et al., 2011; Schmidt \& Hunter, 1998). Structured interviews also increase fairness, as unstructured interviews may increase the likelihood of sociocognitive biases negatively impacting certain groups (Buckley et al., 2007; Roth et al., 2002). For example, in one of the only studies on interviews in the graduate application process, Burmeister et al. (2013) found that a higher body mass index was related to fewer post-interview offers for graduate school. Importantly, adding structure to interviews has been shown to reduce the impact of sociocognitive biases (Kutcher \& Bragger, 2004; Sacco et al., 2003). Taken together, extrapolating from the research on employment interviews indicates that interviews used for graduate admissions should be structured rather than unstructured. Perhaps worth noting is that interviewing for graduate school can also be expensive, as students may be required to pay for their travel in part or in full and may also be required to request time off from work. There is also the time required to prepare for the interview that needs to be factored in. Such costs_ — as well as the cost of applying to graduate school in general—may be a real or perceived barrier for students from low SES backgrounds.

\section{GRE}


There is strong meta-analytic support for the validity of GRE scores for predicting graduate GPA (first-year and cumulative), scores on comprehensive exams, and faculty ratings of graduate student performance (Kuncel et al., 2001) ${ }^{6}$. More specifically, according to Kuncel et al.'s (2001) meta-analysis, GRE-Verbal has a sample weighted mean validity of $r=.23$ ( $\rho=.34$ after correcting for range restriction and measurement error in the criterion) when predicting GGPA, $r=.24(\rho=.34)$ when predicting first-year GGPA, $r=.34(\rho=.44)$ when predicting comprehensive exam scores, and $r=.23(\rho=.42)$ when predicting faculty-rated graduate school performance. GRE-Quantitative has a sample weighted mean validity of $r=.21(\rho=.32)$ when predicting GGPA, $r=.24(\rho=.38)$ when predicting first-year GGPA, $r=.19(\rho=.26)$ when predicting comprehensive exam scores, and $r=.25(\rho=.47)$ when predicting faculty-rated graduate school performance. Additionally, when using a unit-weighted composite, the GRE-V + GRE-Q had a predictive validity of $R=.46$ (in predicting a unit-weighted composite of GGPA and faculty rated graduate school performance). A research team at ETS (Burton \& Wang, 2005) conducted another meta-analytic review of the GRE's predictive validity using data obtained from 21 departments across seven different universities, which largely replicated findings from the Kuncel et al. study. ${ }^{7}$

Notably, Kuncel et al. (2001) found that the GRE had weaker relationships with degree attainment (Verbal $r=.14$; Quantitative $r=.17$ ), time to completion (Verbal $r=.21$; Quantitative $r=-.08$ ), research productivity (Verbal $r=.07$; Quantitative $r=.08$ ), and publication citation count (Verbal $r=.13$; Quantitative $r=.17$ ). Thus, these criteria likely benefit

\footnotetext{
${ }^{6}$ Also see Appendix B for our review of several studies that reached contrarian conclusions regarding evidence for the criterion-related validity of inferences drawn from GRE scores.

${ }^{7}$ Another noteworthy observation from these meta-analyses (Burton \& Wang, 2005; Kuncel et al., 2001) is that the effect sizes within psychology and/or social sciences were typically as strong (if not stronger) across most criteria.
} 
from the measurement of additional noncognitive predictors such as motivation or conscientiousness. These results remain consistent when examining graduate student success in both Master's and Ph.D. programs (Kuncel et al., 2010) and fairly consistent across disciplines (Kuncel et al., 2001). Additionally, Arneson et al. (2011) found support for the "more-is-better" hypothesis, which suggests that there are no diminishing returns for admitting students at the upper range of GRE scores.

The GRE subject tests also have strong predictive validity evidence, with a sample weighted mean validity of $r=.31(\rho=.41)$ when predicting GGPA, $r=.34(\rho=.45)$ when predicting first-year graduate GPA, $r=.43(\rho=.51$ when predicting comprehensive exam scores, and $r=.30(\rho=.50)$ when predicting faculty-rated graduate school performance (Kuncel et al., 2001). Much like the GRE-Q and GRE-V, the Subject test had weaker relationships with time to completion $(r=.02)$, research productivity $(r=.17)$, and publication citation count $(r=.20)$. Unlike the Quantitative and Verbal tests, however, the Subject tests were especially powerful predictors of degree attainment with $r=.32(\rho=.39)$. The predictive value of the GRE subject test generalized across the humanities, social sciences, life sciences, and math-physical sciences subdisciplines examined by Kuncel and colleagues (2001). Additionally, when considering a unit-weighted composite, the GRE-V + GRE-Q + GRE-Subject had a predictive validity of $R=$ .52 in predicting a composite measure of GGPA and faculty-rated graduate school performance. Despite strong research support for the predictive validity of GRE scores, the GRE has received a number of criticisms primarily centered around bias and fairness. These concerns are likely a result of the significant differences in mean scores across different subgroups. Based on data released by ETS (2019), on average, Black Americans score .92 standard deviations below White Americans and .78 standard deviations below Asian Americans on the GRE-V. Hispanic 
Americans score between .58 and .67 standard deviations below White Americans, .46 and .55 standard deviations below Asian Americans, and .24 to .33 above Black Americans on the GREV (depending on the Hispanic subgroup considered). The subgroup differences get larger when considering average GRE-Q scores; Black Americans score .97 standard deviations below White Americans and 1.32 standard deviations below Asian Americans. Hispanic Americans score .84.97 standard deviations below Asian Americans, .48-.61 standard deviations below White Americans, and .33-.46 above Black Americans on the GRE-Q (depending on the Hispanic subgroup considered). Pennock-Román (1993) found that when tracking students who took both the SAT and GRE, the racial subgroup differences stay fairly stable across time, with only a small narrowing of the gap. In addition to racial subgroup differences, there are also smaller gender differences, as women score on average, approximately half a standard deviation below men on the GRE-Q (Bleske-Rechek \& Browne, 2014). Such score differences may impact whether certain subgroups are successfully admitted into graduate programs and may discourage certain subgroups from even applying in the first place. Notably, however, Bleske-Rechek and Browne (2014) demonstrated that although racial and gender gaps have persisted across time (1982-2007), enrollment of women and minorities in STEM fields has increased over time, suggesting that racial and gender gaps in GRE scores alone do not prevent minorities and women from attending graduate school.

As we outline in the section above, the presence of subgroup differences does not inherently imply that the test is biased ${ }^{8}$. When considering whether the GRE is "biased" we can

\footnotetext{
${ }^{8}$ It is noteworthy that within the college admissions context, large-scale studies (e.g., the widely-known February 2020 University of California Task Force report; https://senate.universityofcalifornia.edu/ files/committees/sttf/sttfreport.pdf) have not revealed any substantial evidence that use of standardized tests such as SAT and ACT in school admissions perpetuates racial disparities; rather, data suggest that the tests are the best predictors of success across all groups, and thus likely help identify talented URM students who may otherwise be overlooked in the admissions process. We also note that research to date shows mixed/ambiguous evidence for the test-optional policy leading to
} 
look at differential test/item functioning (i.e., measurement bias) or differential prediction (i.e., predictive bias). Past research has found that GRE and SAT item difficulty does influence differential item functioning for Black and White test takers (Santelices \& Wilson, 2012; Scherbaum \& Goldstein, 2008). Specifically, Black test takers were less likely than White testtakers of the same ability (i.e., equal test scores) to respond correctly to easy items but were more likely to respond correctly to difficult items. Research using SAT data has also found that these results are not an artifact of statistical methods (Santelices \& Wilson, 2012). For interested readers, Appendix B summarizes ETS's 40-year effort to delineate, identify, and address measurement bias in the GRE.

With respect to predictive bias (i.e., differential prediction), several studies have concluded that predictive bias does not appear to be an issue using the GRE. For example, Ling and colleagues (2020) examined differential prediction between students without reported disabilities, students with reported disabilities who received accommodations, and students with reported disabilities who did not receive accommodations. Although ultimately relying on a relatively small sample of students with disabilities ( $n=103$ and 283), the researchers found only minimal evidence of differential prediction between students without disabilities and students with disabilities (with or without accommodation); the differential prediction varied across disability subtype ranging from none to minimal. These results are also consistent with research conducted by ETS and summarized by Braun and Jones (1984). After cross-validating their findings, these authors concluded that there was no evidence of differential prediction on the basis of age, sex, or race (data collected on a sample of $n=2747$ students in $\mathrm{k}=121$ departments

more enrollments of URM students (e.g., Belasco et al., 2015; Syverson et al., 2018), signaling the need for more systematic and rigorous investigations in the coming years. 
(developmental sample) and $n=2744$ students in $\mathrm{k}=121$ departments (cross-validation sample)).

Considering admissions tests more generally, Kuncel and Hezlett (2007) noted that research had found limited evidence of differential prediction by race or ethnic group, but when differential prediction is observed, it tends to favor minority groups. There is also a large body of research examining and debating whether the SAT demonstrates differential prediction (e.g., Aguinis et al., 2010; Berry et al., 2011; Dahlke et al., 2019; Fischer et al., 2013; Mattern \& Patterson, 2013). The general consensus from this research is that the SAT tends to overpredict UGPAs for Black students compared to White students and tends to underpredict UGPAs for women compared to men.

In summary, there is very limited evidence for psychometric bias - i.e., differential item functioning in the GRE items (see Appendix B). In addition, given the consistent finding that other admissions tests lack predictive bias (i.e., they do not underestimate minority performance), we see no reason to expect the GRE to manifest predictive bias. Instead, if any differential prediction is present, it most likely favors URM students over White students. Thus, omitting or down-weighting GRE scores is likely to hurt qualified minority candidates relative to qualified White candidates. Nevertheless, we encourage future efforts to verify that the patterns found in other tests (e.g., SAT) generalize to GRE. Importantly, we also encourage future research to apply the same level of scrutiny of psychometric and predictive bias to other forms of assessments.

Issues of measurement and predictive bias aside, a bigger issue of fairness deserves thoughtful deliberations amongst those in higher education. We believe that subgroup differences in test scores strongly signal the presence of systemic inequalities in opportunities and resources 
that have persisted over multiple generations, which must be carefully examined and corrected (Jencks \& Phillips, 1998). It is important to note that standardized test scores such as the GRE can only measure what the test-takers are capable of at the time of testing (i.e., the person's current abilities, knowledge, and skills); they do not indicate what they will be able to do in a later point in time (there is an empirically-established predictive relationship between the two, but the GRE scores themselves do not measure the person's future abilities). The person's current level of abilities, knowledge, and skills (as indicated by test scores) is likely to improve with future training and development and is undoubtedly influenced by past educative and developmental experiences that are often unevenly distributed across different racial groups. Given this, the problem of test score disparities in school admissions must be tackled not only from a psychometric perspective but also from sociological, economic, educational/developmental, psychological, cultural/anthropological, and even philosophical perspectives (e.g., Outtz \& Newman, 2010; Shewach et al., 2019).

\section{Summary and Reflections}

After reviewing the literature, we noticed a few trends. First, there is a much larger body of research on the validity, bias, and fairness of the GRE and UGPA than other assessment methods used in graduate admission. Both of these quantitative assessment methods (i.e., the GRE and UGPA) have received strong support as predictors of graduate student success. For example, Table 3 summarizes the results of several meta-analyses examining predictors of graduate school success. The simple, bivariate and uncorrected, mean correlations between GRE scores and most indicators of graduate school success tended to fall in the range of $\bar{r}=.15$ to $\bar{r}$ 
$=.30$. Following corrections for range restriction and measurement error, most of the corrected correlations fell in the $\hat{\rho}=.20$ to .50 range $^{9}$.

A few notable exceptions were the relationships between GRE scores and indicators of degree attainment, time to completion, and research productivity. However, for some of these variables, there was considerable heterogeneity in effect sizes as a function of discipline. For example, ignoring discipline, GRE scores were relatively modest predictors of degree attainment with sample-weighted uncorrected (corrected) correlations of .14 (.18), .14 (.20), .08 (.11), and .32 (.39), for GRE-V, GRE-Q, GRE-A, and GRE-S, respectively. However, within the social sciences, the GRE was a strong predictor of degree attainment with uncorrected (corrected) mean correlations of $.17(.22), .22(.31), .37(.40)$, and .24 (.30) for GRE-V, GRE-Q, GRE-A, and GRE-S, respectively.

Despite its predictive validity, the GRE has also received a fair amount of criticism, with many fields currently advocating for abolishing the GRE from the admissions process. To be sure, the GRE is not without its problems; the large subgroup differences may discourage many underrepresented groups from applying or being admitted into graduate programs. However, the GRE does not appear to be tainted by measurement bias, nor does it appear to suffer from predictive bias that would disadvantage students from URM groups. Instead, any predictive bias is likely to benefit students from URM groups.

What is less well understood and/or more debatable is whether the other (less standardized and more qualitative) methods of assessment used in graduate admissions are

\footnotetext{
${ }^{9}$ Correlation coefficients need to be put in a specific context to be more readily interpretable for their practical significance. Kuncel et al. (2001) provided an excellent discussion of this topic (see p. 176 of their paper), where they illustrated that a predictor-criterion correlation of .10 can increase the percentage of successful graduate students from $50 \%$ to $57 \%$ (assuming the selection ratio of .10 and base rate of .50), whereas a correlation of .41 (which is the case for GRE Subject Test in predicting graduate GPA) increase the percentage from 50\% to $78 \%$ (with the same selection ratio and base rate).
} 
predictively valid, unbiased, and fair. Although these methods are commonly used, the relative lack of systematic research on their psychometric properties (e.g., validity, bias) is problematic, especially if graduate programs opt to abandon the GRE and rely solely on these other more qualitative and subjective methods.

Meta-analytic findings on personal statements and prior research experience suggest that these generally do not predict graduate student success very well (Miller et al., 2021; Murphy et al., 2009; See Table 3). However, these findings are based on a rather small number of primary studies (and the numerical ratings used in the primary studies were not generated using a standardized protocol that is applied consistently across samples), and thus more research is needed to explore these questions further. Research is particularly limited as to what information gleaned from Resumes/CVs and interviews are valuable for predicting graduate school success and why. The lack of construct validity evidence for personal statements and Resumes/CVs may stem from these methods' unstructured nature. It is unclear what information is collected or how it is combined (e.g., weighed) when making graduate admission decisions. It is worth noting that a recent meta-analytic study in the college admissions context suggested more structured measures of biodata (i.e., a person's past history and experiences) can predict college student outcomes such as grades and citizenship (Zhang \& Kuncel, 2020). Similarly, research to date suggests that letters of recommendation may provide some limited incremental validity over GRE and UGPA when attempting to predict outcomes such as persistence in graduate school. Adding more structure and standardization may increase the validity and reliability of both personal statements and letters of recommendation, thereby increasing their value in the application process. 
As we discussed earlier, these qualitative assessment methods (i.e., resumes/CVs, personal statements, letters of recommendation, and unstructured interviews) often lend themselves to sociocognitive and rater biases. These methods may also contribute to disparate admission outcomes that are unfair to URM students due to a lack of access to informational resources or barriers to seeking faculty support. Notably, systematic research on bias and fairness is sorely lacking for these methods, and many of the conclusions currently drawn come from contexts outside graduate admissions (e.g., employment interviews).

Finally, it is important to note that some (e.g., Niessen \& Meijer, 2017) have cautioned against the use of noncognitive predictors in high-stakes contexts, as would be the case in graduate admissions. Specifically, concerns have been raised about the extent to which noncognitive predictors are prone to potential faking or coaching effects. Thus, future research involving noncognitive predictors of performance (e.g., personality traits such as achievement motivation or self-efficacy) should include evaluations of faking/coaching - not only in laboratory settings but also in actual, high-stakes testing contexts.

\section{PART 3: MULTIPLE WAYS FORWARD}

First and foremost, we call for broad and fundamental changes to the educational institutions (early childhood through graduate schools) and to society at large to ensure equal opportunities exist for URM students, as well as an inclusive and supportive environment for everyone to succeed. To this end, we suggest that colleges and universities invest in developing a healthy pipeline of URM students whose career interests align with necessary KSAOs (knowledge, skills, abilities, and other characteristics) needed in the specific graduate career field. This could be done through more personalized and targeted career counseling and longterm recruiting from the early years of college or even before college entry. Currently, the focus 
is on graduate diversity visitation programs that enable URM applicants to visit graduate programs just as they begin submitting their applications.

To address the aforementioned issues of fairness related to 'equal opportunities for high test performance,' ETS implements a fee reduction program for GRE takers with financial needs (ETS, n.d.-b). There are also a number of free test preparation options from ETS, Kaplan, as well as other websites that offer information about test-taking strategies, practice tests, and flashcards (e.g., quizlet.com). Educating undergraduate students, particularly URM students, about these materials may help them effectively prepare for the GRE at no financial cost ${ }^{10}$. We also suggest that taking a more targeted approach by providing URM students with additional resources (e.g., mentoring) may be a highly effective way to address fairness concerns with non-GRE assessments (e.g., 'who gets to be recommended highly by important people in the field?'; 'who gets to have extensive research experiences while others have to work to pay for tuition and living expenses during college?'). Providing effective mentorship to URM students and opportunities for quality research experiences is crucial for increasing access to research experiences, letters of recommendation, and knowledge on how to effectively apply to graduate programs (Ahmad et al., 2019). Research experiences also increase the likelihood that URM students pursue post-graduate education (Carpi et al., 2017). Also, we suggest that graduate programs develop long-term financial strategies (e.g., fee waivers) for reducing the cost of applying to graduate programs for URM students. Taken together, increasing the diversity of our graduate programs requires a diverse pipeline of qualified URM students. Pipeline diversity can be increased through increased access to resources and targeted mentoring for URM students.

\footnotetext{
${ }^{10}$ Although there is limited research on the efficacy of admissions test preparation courses, available research on the SAT suggests that these preparation courses likely have a small impact on the test scores (e.g., Briggs, 2002; Powers \& Rock, 1999). Extrapolating from this, we speculate that GRE coaching/prep services may also have a modest impact on test scores and that students with higher SES are more likely to avail themselves of these services.
} 
Although these institutional and societal changes take tremendous time and effort, there are also a number of immediate to intermediate solutions that each and every graduate program can adopt, which focus on improving the psychometric quality of graduate admission assessments and selection decisions (i.e., interventions that can be immediately implemented to help concerns related to criterion-related validity and bias).

\section{Practical Recommendations for Improving Graduate Admissions Decisions}

We strongly recommend that all graduate programs incorporate more standardization, objectivity, and transparency in their admission processes. Standardization is a critical step toward addressing the validity and bias concerns that we outlined above. We suggest the following protocol for graduate programs seeking to immediately address potential concerns over predictive validity and bias (more details are included in Appendix C): (1) Decide on predictor constructs of interest; (2) Link the predictor constructs to the existing assessment methods in an explicit, quantitative, and standardized manner (e.g., create a 'grading rubric' for all measures and conduct a frame-of-reference training); (3) Decide how all information gathered from the entire admission process will be systematically recorded, assessed, and integrated into a final decision; (4) Integrate constructs of interest into graduate student development and evaluation; and (5) Use such evaluations as well as other criteria identified to evaluate the selection system over time (AERA et al., 2014; Binning \& Barrett, 1989; SIOP, 2018).

As a longer-term improvement strategy, we also recommend clarifying the constructmeasurement linkages for all predictors and criteria as they apply to each graduate program. At this point, the psychometric literature is not mature enough to dictate what specific measures should be used for specific KSAOs required for a given academic discipline (we will come back to this in the following section). However, each graduate program can implement a tailored 
approach to designing their own set of criteria and measures (following the guidelines in Appendix C) and deciding which predictor measures will maximize the criteria of success as they have defined it. We recommend making this predictor-criterion linkage explicit and accessible to all parties involved, from prospective/actual applicants to current graduate students and faculty advisors (and graduate admission committee members) for maximum transparency and equity.

\section{Future Research Directions}

We call for additional psychometric work addressing limitations of all assessment and selection techniques currently used in graduate admissions. We highlight three major directions in this domain. First, there needs to be a clear mapping of predictor constructs of interest ("what are the specific knowledge, skills, abilities, and other characteristics predictive of graduate school success?") to the methods of assessment, as mentioned above. To inform such decisions, we need more research on what predicts graduate school success and what methods are best suited for measuring such predictor constructs.

On the predictor side, the GRE is designed to measure verbal reasoning, quantitative reasoning, and analytical writing abilities. On the other hand, many psychologists have not explicitly mapped the other assessment methods onto "job-relevant" constructs. In the current literature, empirical studies have focused on the observed correlations and regression weights associated with measures (rather than constructs) of predictors for a limited set of criterion measures (e.g., 'does undergraduate GPA predict graduate GPA?'). As such, little is known about the specific set of KSAOs that are the targets of measurement when using the remaining predictor measures (e.g., GPA, interviews, letters of recommendation, resumes/CVs). This is highly problematic from practical, psychometric, and legal perspectives, as one cannot discuss 
whether inferences from a measure are valid unless there is a clear purpose (or intended use) for the measure (i.e., what construct is the measure supposed to capture; how will the measure be used, and what justification or evidence exists for using the measure in this manner?).

On the criterion side, questions remain as to what we consider 'success' in graduate schools. As shown in Figure 1, the indicators (or measures) of success that are currently utilized are best considered as formative (or causal) indicators, not reflect (or effect) indicators. In other words, it is more appropriate to view these indicators as observed variables that form a construct (or a latent variable) of graduate school success rather than to view them as reflective of an underlying construct of success. As such, it is critical for us in higher education to critically evaluate whether the current metrics of success themselves are valid, unbiased, and fair (White et al., 2020).

Second, more research is needed on how standardizing the currently unstructured and qualitative assessment methods - i.e., personal statements, letters of recommendation, and graduate admission interviews - will affect validity and bias issues. Similarly, systematic, largescale (multilevel) investigations are needed on the impact of integration and decision-making processes on validity and fairness outcomes across graduate programs. An additional (and perhaps most limiting) hurdle to doing research in this area is obtaining access to sufficiently large samples to allow for reliable and generalizable multilevel investigations. Furthermore, graduate programs are often idiosyncratic in what they select for (especially when considering "fit"). In view of this, we return to our recommendation above, calling for greater transparency at the level of individual graduate programs and for these programs to begin the process of standardizing and evaluating their selection procedures to accumulate data that could be used to provide evidence related to predictive validity, measurement bias, and fairness. 
Third, there has been extensive research on GREs in terms of measurement bias and predictive bias, but a psychometric framework can also be applied to other predictors such as undergraduate GPA, personal statements, resumes/CVs, letters of recommendation, and interviews. For example, concerning measurement bias, given the same verbal presentation in an interview, do faculty interviewers provide systematically different scores to underrepresented minorities? Apart from the psychometric framework, one can apply the theoretical frameworks of the Brunswik lens model (Brunswik, 1956) or the Realistic Accuracy Model (Funder, 1995) to study bias from the social cognition perspective. Broadly, both models provide ways of understanding how subjective judgments of applicants are formed through the applicant's behaviors. These behaviors may be (ir)relevant, (un)available, (un)detected, and (un)utilized by observers and can be the basis for understanding sociocognitive biases in personal statements, letters of recommendation, and interviews.

\section{Closing thoughts}

A number of positive changes have been made over the years to improve equity, diversity, and inclusion of higher education. Nevertheless, there is still significant work ahead to ensure that graduate training programs recruit, select, train, and place their students in a valid, unbiased, and fair manner. We invite everyone in the field of psychology to carefully evaluate the current evidence presented and utilize their expertise and training in scientific methods to improve the validity and fairness of graduate admissions decisions. Psychologists from many different sub-disciplines (educational, social, cognitive, and industrial, just to name a few) are poised to offer unique and important perspectives related to validity, bias, and fairness in graduate school admissions. It may also be worth noting that there are different views on test and measurement, especially regarding what validity, bias, and fairness mean, and how race plays a 
role in assessing one's academic abilities for selection purposes. A contemporary psychometric perspective is indeed one of the many perspectives that should be invited to contribute to this conversation and future conversations that seek to address the issue of racial equity and justice in academia. We hope this article serves as a catalyst for meaningful conversations that engender appropriate changes to the graduate admissions process - changes that are anchored on robust and rigorous science. 


\section{References}

Aguinis, H., Culpepper, S. A., \& Pierce, C. A. (2010). Revival of test bias research in preemployment testing. Journal of Applied Psychology, 95(4), 648-680. https://doi.org/10.1037/a0018714

Ahmad, A. S., Sabat, I., Trump-Steele, R., \& King, E. (2019). Evidence-Based Strategies for Improving Diversity and Inclusion in Undergraduate Research Labs. Frontiers in Psychology, 10. https://doi.org/10.3389/fpsyg.2019.01305

Aisch, G., Buchanan, L., Cox, A., \& Quealy, K. (2017, January 18). Some Colleges Have More Students From the Top 1 Percent Than the Bottom 60. Find Yours. The New York Times. https://www.nytimes.com/interactive/2017/01/18/upshot/some-colleges-have-morestudents-from-the-top-1-percent-than-the-bottom-60.html, https://www.nytimes.com/interactive/2017/01/18/upshot/some-colleges-have-morestudents-from-the-top-1-percent-than-the-bottom-60.html

American Educational Research Association, American Psychological Association, \& National Council on Measurement in Education. (2014). Standards for educational and psychological testing. Washington, DC: American Educational Research Association.

Arneson, J. J., Sackett, P. R., \& Beatty, A. S. (2011). Ability-Performance Relationships in Education and Employment Settings: Critical Tests of the More-ls-Better and the GoodEnough Hypotheses. 22(10), 1336-1342.

Babal, J. C., Gower, A. D., Frohna, J. G., \& Moreno, M. A. (2019). Linguistic analysis of pediatric residency personal statements: gender differences. BMC Medical Education, 19(1), 392. https://doi.org/10.1186/s12909-019-1838-x 
Banerjee, R., Reitz, J. G., \& Oreopoulos, P. (2018). Do Large Employers Treat Racial Minorities More Fairly? An Analysis of Canadian Field Experiment Data. Canadian Public Policy. https://doi.org/10.3138/cpp.2017-033

Bangera, G., \& Brownell, S. E. (2014). Course-Based Undergraduate Research Experiences Can Make Scientific Research More Inclusive. CBE_Life Sciences Education, 13(4), 602606. https://doi.org/10.1187/cbe.14-06-0099

Barrick, M. R., Shaffer, J. A., \& DeGrassi, S. W. (2009). What you see may not be what you get: relationships among self-presentation tactics and ratings of interview and job performance. Journal of Applied Psychology, 94(6), 1394.

Baxter, J. C., Brock, B., Hill, P. C., \& Rozelle, R. M. (1981). Letters of Recommendation: A Question of Value. Journal of Applied Psychology, 66(3), 296-301.

Belasco, A. S., Rosinger, K. O., \& Hearn, J. C. (2015). The Test-Optional Movement at America's Selective Liberal Arts Colleges: A Boon for Equity or Something Else? Educational Evaluation and Policy Analysis, 37(2), 206-223. https://doi.org/10.3102/0162373714537350

Berry, C. M. (2015). Differential Validity and Differential Prediction of Cognitive Ability Tests: Understanding Test Bias in the Employment Context. Annual Review of Organizational Psychology and Organizational Behavior, 2(1), 435-463. https://doi.org/10.1146/annurev-orgpsych-032414-111256

Berry, C. M., Clark, M. A., \& McClure, T. K. (2011). Racial/ethnic differences in the criterionrelated validity of cognitive ability tests: A qualitative and quantitative review. Journal of Applied Psychology, 96(5), 881-906. https://doi.org/10.1037/a0023222 
Bertrand, M., \& Mullainathan, S. (2004). Are Emily and Greg More Employable Than Lakisha and Jamal? A Field Experiment on Labor Market Discrimination. American Economic Review, 94(4), 991-1013. https://doi.org/10.1257/0002828042002561

Betts, J. R., \& Morell, D. (1999). The Determinants of Undergraduate Grade Point Average: The Relative Importance of Family Background, High School Resources, and Peer Group Effects. The Journal of Human Resources, 34(2), 268-293. https://doi.org/10.2307/146346

Binning, J. F., \& Barrett, G. V. (1989). Validity of personnel decisions: A conceptual analysis of the inferential and evidential bases. Journal of Applied Psychology, 74(3), 478-494. https://doi.org/10.1037/0021-9010.74.3.478

Bleske-Rechek, A., \& Browne, K. (2014). Trends in GRE scores and graduate enrollments by gender and ethnicity. Intelligence, 46, 25-34. https://doi.org/10.1016/j.intell.2014.05.005

Borsboom, D. (20041012). The Concept of Validity. Psychological Review; US: American Psychological Association. https://doi.org/10.1037/0033-295X.111.4.1061

Bosco, F. A., Aguinis, H., Singh, K., Field, J. G., \& Pierce, C. A. (2015). Correlational effect size benchmarks. Journal of Applied Psychology, 100(2), 431-449. https://doi.org/10.1037/a0038047

Brunswik, E. (1956). Perception and the representative design of psychological experiments, 2nd ed. University of California Press.

Buckley, M. R., Jackson, K. A., Bolino, M. C., VERES III, J. G., \& Feild, H. S. (2007). The influence of relational demography on panel interview ratings: A field experiment. Personnel Psychology, 60(3), 627-646. 
Burmeister, J. M., Kiefner, A. E., Carels, R. A., \& Musher-Eizenman, D. R. (2013). Weight bias in graduate school admissions: Weight Bias Graduate Admissions. Obesity, 21(5), 918920. https://doi.org/10.1002/oby.20171

Burton, N. W., \& Wang, M. (2005). Predicting Long-Term Success in Graduate School: A Collaborative Validity Study. ETS Research Report Series, 2005(1), i-61. https://doi.org/10.1002/j.2333-8504.2005.tb01980.x

Campion, M. A., Palmer, D. K., \& Campion, J. E. (1997). A review of structure in the selection interview. Personnel Psychology, 50(3), 655-702.

Carpi, A., Ronan, D. M., Falconer, H. M., \& Lents, N. H. (2017). Cultivating minority scientists: Undergraduate research increases self-efficacy and career ambitions for underrepresented students in STEM. Journal of Research in Science Teaching, 54(2), 169-194. https://doi.org/10.1002/tea.21341

CDC. (2020, April 30). Communities, Schools, Workplaces, \& Events. Centers for Disease Control and Prevention. https://www.cdc.gov/coronavirus/2019-ncov/community/healthequity/race-ethnicity.html

Chapell, M. S., Blanding, Z. B., Silverstein, M. E., Takahashi, M., Newman, B., Gubi, A., \& McCann, N. (2005). Test Anxiety and Academic Performance in Undergraduate and Graduate Students. Journal of Educational Psychology, 97(2), 268-274. https://doi.org/10.1037/0022-0663.97.2.268

Chapman, D. S., \& Zweig, D. I. (2005). Developing a nomological network for interview structure: Antecedents and consequences of the structured selection interview. Personnel Psychology, 58(3), 673-702. 
Chari, D., \& Potvin, G. (2019). Understanding the importance of graduate admissions criteria according to prospective graduate students. Physical Review Physics Education Research, 15(2), 023101. https://doi.org/10.1103/PhysRevPhysEducRes.15.023101

Chin, M. J., Quinn, D. M., Dhaliwal, T. K., \& Lovison, V. S. (2020). Bias in the Air: A Nationwide Exploration of Teachers' Implicit Racial Attitudes, Aggregate Bias, and Student Outcomes. Educational Researcher, 0013189X20937240. https://doi.org/10.3102/0013189X20937240

Cleary, T. A. (1968). Test Bias: Prediction of Grades of Negro and White Students in Integrated Colleges. Journal of Educational Measurement, 5(2), 115-124. https://doi.org/10.1111/j.1745-3984.1968.tb00613.x

Cohn, E., Cohn, S., Balch, D. C., \& Bradley, J. (2004). Determinants of undergraduate GPAs: SAT scores, high-school GPA and high-school rank. Economics of Education Review, 23(6), 577-586. https://doi.org/10.1016/j.econedurev.2004.01.001

Colella, A., Hebl, M., \& King, E. (2017). One hundred years of discrimination research in the Journal of Applied Psychology: A sobering synopsis. Journal of Applied Psychology, 102(3), 500-513. https://doi.org/10.1037/ap10000084

Conway, J. M., Jako, R. A., \& Goodman, D. F. (1995). A meta-analysis of interrater and internal consistency reliability of selection interviews. Journal of Applied Psychology, 80(5), 565.

Coronado, G. D., Shuster, M., Ulrich, A., Anderson, J., \& Loest, H. (2012). Strategies for Diversifying the Pool of Graduate Students in Biomedical Sciences. Journal of Cancer Education, 27(3), 436-442. https://doi.org/10.1007/s13187-012-0374-8 
Cortina, J. M., Goldstein, N. B., Payne, S. C., Davison, H. K., \& Gilliland, S. W. (2000). The incremental validity of interview scores over and above cognitive ability and conscientiousness scores. Personnel Psychology, 53(2), 325-351.

Dahlke, J. A., Sackett, P. R., \& Kuncel, N. R. (2019). Effects of range restriction and criterion contamination on differential validity of the SAT by race/ethnicity and sex. Journal of Applied Psychology, 104(6), 814-831. https://doi.org/10.1037/ap10000382

Dawes, R. M., Faust, D., \& Meehl, P. E. (1989). Clinical versus actuarial judgment. Science, 243(4899), 1668-1674. https://doi.org/10.1126/science.2648573

de Ayala, R. J. (2009). The theory and practice of item response theory. Guilford Press.

Dovidio, J. F., \& Fiske, S. T. (2012). Under the Radar: How Unexamined Biases in DecisionMaking Processes in Clinical Interactions Can Contribute to Health Care Disparities. American Journal of Public Health, 102(5), 945-952. https://doi.org/10.2105/AJPH.2011.300601

Drasgow, F. (1984). Scrutinizing psychological tests: Measurement equivalence and equivalent relations with external variables are the central issues. Psychological Bulletin, 95(1), 134-135. https://doi.org/10.1037/0033-2909.95.1.134

Drasgow, F. (1987). Study of the measurement bias of two standardized psychological tests. Journal of Applied Psychology, 72(1), 19-29. https://doi.org/10.1037/0021-9010.72.1.19

Einhorn, H. J., \& Hogarth, R. M. (1978). Confidence in judgment: Persistence of the illusion of validity. Psychological Review, 85(5), 395-416. https://doi.org/10.1037/0033295X.85.5.395

ETS. (n.d.-a). About the GRE General Test (For Test Takers). Retrieved August 11, 2020, from https://www.ets.org/gre/revised_general/about 
ETS. (n.d.-b). GRE Fee Reduction Program (For Test Takers). Retrieved August 12, 2020, from https://www.ets.org/gre/revised_general/about/fees/reductions

ETS. (2012). GRE General test score information by Ethnicity/Racial groups, 2009-2010.

Educational Testing Service.

ETS. (2019). A Snapshot of the Individuals Who Took the GRE General Test July 2014-June 2019. $1-68$.

Fischer, F. T., Schult, J., \& Hell, B. (2013). Sex-specific differential prediction of college admission tests: A meta-analysis. Journal of Educational Psychology, 105(2), 478-488. https://doi.org/10.1037/a0031956

Fletcher, J., \& Tienda, M. (2010). Race and Ethnic Differences in College Achievement: Does High School Attended Matter? The ANNALS of the American Academy of Political and Social Science, 627(1), 144-166. https://doi.org/10.1177/0002716209348749

Freedle, R., \& Kostin, I. (1990). Item Difficulty of Four Verbal Item Types and an Index of Differential Item Functioning for Black and White Examinees. Journal of Educational Measurement, 27(4), 329-343. https://doi.org/10.1111/j.1745-3984.1990.tb00752.x

Friedman, R., Fang, C. H., Hasbun, J., Han, H., Mady, L. J., Eloy, J. A., \& Kalyoussef, E. (2017). Use of standardized letters of recommendation for otolaryngology head and neck surgery residency and the impact of gender: Gender and Letter of Recommendations. The Laryngoscope, 127(12), 2738-2745. https://doi.org/10.1002/lary.26619

Funder, D. C. (1995). On the accuracy of personality judgment: A realistic approach. Psychological Review, 102(4), 652-670. https://doi.org/10.1037/0033-295X.102.4.652 
Grimm, L. J., Redmond, R. A., Campbell, J. C., \& Rosette, A. S. (2020). Gender and Racial Bias in Radiology Residency Letters of Recommendation. Journal of the American College of Radiology, 17(1, Part A), 64-71. https://doi.org/10.1016/j.jacr.2019.08.008

Grove, W. M., Zald, D. H., Lebow, B. S., Snitz, B. E., \& Nelson, C. (2000). Clinical versus mechanical prediction: a meta-analysis. Psychological Assessment, 12(1), 19-30.

Hall, J. D., O’Connell, A. B., \& Cook, J. G. (2017). Predictors of Student Productivity in Biomedical Graduate School Applications. PLoS ONE, 12(1). https://doi.org/10.1371/journal.pone.0169121

Harsh, J. A., Maltese, A. V., \& Tai, R. H. (2012). A Perspective of Gender Differences in Chemistry and Physics Undergraduate Research Experiences. Journal of Chemical Education, 89(11), 1364-1370. https://doi.org/10.1021/ed200581m

Hasher, L., Goldstein, D., \& Toppino, T. (1977). Frequency and the conference of referential validity. Journal of Verbal Learning \& Verbal Behavior, 16(1), 107-112. https://doi.org/10.1016/S0022-5371(77)80012-1

Hersch, J. (2019). Catching up Is Hard to Do: Undergraduate Prestige, Elite Graduate Programs, and the Earnings Premium (No. 12609; pp. 1-61). Institute of Labor Economics (IZA).

Highhouse, S., \& Kostek, J. A. (2013). Holistic assessment for selection and placement. In APA handbook of testing and assessment in psychology, Vol. 1: Test theory and testing and assessment in industrial and organizational psychology (pp. 565-577). American Psychological Association. https://doi.org/10.1037/14047-031

Holder, W. B. (1962). Letters of recommendation. American Psychologist, 506-507. 
Houser, C., \& Lemmons, K. (2018a). Implicit bias in letters of recommendation for an undergraduate research internship. Journal of Further and Higher Education, 42(5), 585595. https://doi.org/10.1080/0309877X.2017.1301410

Houser, C., \& Lemmons, K. (2018b). Implicit bias in letters of recommendation for an undergraduate research internship. Journal of Further and Higher Education, 42(5), 585595. https://doi.org/10.1080/0309877X.2017.1301410

Hoyt, W. T. (2000). Rater bias in psychological research: When is it a problem and what can we do about it? Psychological Methods, 5(1), 64-86. https://doi.org/10.1037/1082989X.5.1.64

Hu, J. C. (2020). Online GRE test heightens equity concerns. Science, 368(6498), 1414-1414. https://doi.org/10.1126/science.368.6498.1414

Hughey, A. W. (1995). Observed Differences in Graduate Record Examination Scores and Mean Undergraduate Grade Point Averages by Gender and Race among Students Admitted to a Master's Degree Program in College Student Affairs. Psychological Reports, 77(3_suppl), 1315-1321. https://doi.org/10.2466/pr0.1995.77.3f.1315

International Taskforce on Assessment Center Guidelines. (2015). Guidelines and Ethical Considerations for Assessment Center Operations. Journal of Management, 41(4), 1244 1273. https://doi.org/10.1177/0149206314567780

Jaschik, S. (2008, May 22). Non-Cognitive Qualities Join the GRE. https://www.insidehighered.com/news/2008/05/22/non-cognitive-qualities-join-gre Jaschik, S. (2019a, March 18). A look at the many legal ways wealthy applicants have an edge in admissions | Inside Higher Ed. 
https://www.insidehighered.com/admissions/article/2019/03/18/look-many-legal-wayswealthy-applicants-have-edge-admissions

Jaschik, S. (2019b, October 7). Brown follows Princeton in letting departments make the choice on the GRE | Inside Higher Ed.

https://www.insidehighered.com/admissions/article/2019/10/07/brown-follows-princetonletting-departments-make-choice-gre

Jencks, C., \& Phillips, M. (Eds.). (1998). The Black-White test score gap. Brookings Institution Press.

Jones, P. E., \& Roelofsma, P. H. M. P. (2000). The potential for social contextual and group biases in team decision-making: biases, conditions and psychological mechanisms. Ergonomics, 43(8), 1129-1152. https://doi.org/10.1080/00140130050084914

Keiser, H. N., Sackett, P. R., Kuncel, N. R., \& Brothen, T. (2016). Why women perform better in college than admission scores would predict: Exploring the roles of conscientiousness and course-taking patterns. Journal of Applied Psychology, 101(4), 569-581. https://doi.org/10.1037/ap10000069

Khwaileh, F. M., \& Zaza, H. I. (2011). Gender differences in academic performance among undergraduates at the University of Jordan: Are they real or stereotyping? College Student Journal, 45(3), 633-648.

Kim, K. A., Fann, A. J., \& Misa-Escalante, K. O. (2011). Engaging Women in Computer Science and Engineering: Promising Practices for Promoting Gender Equity in Undergraduate Research Experiences. ACM Transactions on Computing Education, 11(2), 1-19. https://doi.org/10.1145/1993069.1993072 
Kim, K., \& Kim, J.-K. (2017). Inequality in the scientific community: the effects of cumulative advantage among social scientists and humanities scholars in Korea. Higher Education, 73(1), 61-77. https://doi.org/10.1007/s10734-015-9980-9

Kim, S., \& Kyllonen, P. C. (2006). Rasch rating scale modeling of data from the standardized letter of recommendation. ETS Research Report Series, 2006(2), i-22. https://doi.org/10.1002/j.2333-8504.2006.tb02038.x

Kim, Y. K., \& Sax, L. J. (2009). Student-Faculty Interaction in Research Universities: Differences by Student Gender, Race, Social Class, and First-Generation Status. Research in Higher Education, 50(5), 437-459. https://doi.org/10.1007/s11162-0099127-X

Kuncel, N. R., \& Hezlett, S. A. (2007). Assessment: Standardized Tests Predict Graduate Students' Success. Science, 315(5815), 1080-1081. https://doi.org/10.1126/science.1136618

Kuncel, N. R., Hezlett, S. A., \& Ones, D. S. (2001). A comprehensive meta-analysis of the predictive validity of the Graduate Record Examinations: Implications for graduate student selection and performance. Psychological Bulletin, 127(1), 162-181. https://doi.org/10.1037/0033-2909.127.1.162

Kuncel, N. R., Klieger, D. M., Connelly, B. S., \& Ones, D. S. (2013). Mechanical versus clinical data combination in selection and admissions decisions: A meta-analysis. Journal of Applied Psychology, 98(6), 1060-1072. https://doi.org/10.1037/a0034156

Kuncel, N. R., Kochevar, R. J., \& Ones, D. S. (2014). A Meta-analysis of Letters of Recommendation in College and Graduate Admissions: Reasons for hope: Letters of 
Recommendation. International Journal of Selection and Assessment, 22(1), 101-107. https://doi.org/10.1111/ijsa.12060

Kuncel, N. R., Wee, S., Serafin, L., \& Hezlett, S. A. (2010). The Validity of the Graduate Record Examination for Master's and Doctoral Programs: A Meta-Analytic Investigation. Educational and Psychological Measurement, 70(2), 340-352. https://doi.org/10.1177/0013164409344508

Kutcher, E. J., \& Bragger, J. D. (2004). Selection Interviews of Overweight Job Applicants: Can Structure Reduce the Bias? 1. Journal of Applied Social Psychology, 34(10), 1993-2022. Kyllonen, P., Walters, A. M., \& Kaufman, J. C. (2005). Noncognitive Constructs and Their Assessment in Graduate Education: A Review. Educational Assessment, 10(3), 153-184. https://doi.org/10.1207/s15326977ea1003_2

Landy, F. J. (1986). Stamp collecting versus science: Validation as hypothesis testing. American Psychologist, 41(11), 1183-1192. https://doi.org/10.1037/0003-066X.41.11.1183

Lang, D. (1987). Equality, Prestige, and Controlled Mobility in the Academic Hierarchy. American Journal of Education, 95(3), 441-467. https://doi.org/10.1086/444314

Larkin, M. (2018, October). Harvard Has Become More Racially Diverse, But Most Of Its Students Are Still Really Rich. https://www.wbur.org/edify/2018/10/24/harvard-diversewealth

Lei, S. A., \& Chuang, N.-K. (2009). Undergraduate research assistantship: A comparison of benefits and costs from faculty and students' perspectives. Education, 130(2), 232-240.

Lin, F., Oh, S. K., Gordon, L. K., Pineles, S. L., Rosenberg, J. B., \& Tsui, I. (2019). Genderbased differences in letters of recommendation written for ophthalmology residency 
applicants. BMC Medical Education, 19(1), 476. https://doi.org/10.1186/s12909-019$1910-6$

Ling, G., Buzick, H., \& Belur, V. (2020). The GRE and Students With Disabilities: A Validity Study at 10 Universities. Exceptional Children, 86(2), 193-208. https://doi.org/10.1177/0014402919872688

Liu, O. L., Minsky, J., Ling, G., \& Kyllonen, P. (2009). Using the Standardized Letters of Recommendation in Selection: Results From a Multidimensional Rasch Model. Educational and Psychological Measurement, 69(3), 475-492. https://doi.org/10.1177/0013164408322031

Lopatto, D. (2007). Undergraduate Research Experiences Support Science Career Decisions and Active Learning. CBE—Life Sciences Education, 6(4), 297-306. https://doi.org/10.1187/cbe.07-06-0039

Lunneborg, P. W., \& Lillie, C. (1973). Sexism in graduate admissions: The letter of recommendation. American Psychologist, 187-189.

Macan, T. (2009). The employment interview: A review of current studies and directions for future research. Human Resource Management Review, 19, 203-218.

Madera, J. M., Hebl, M. R., Dial, H., Martin, R., \& Valian, V. (2019). Raising Doubt in Letters of Recommendation for Academia: Gender Differences and Their Impact. Journal of Business and Psychology, 34(3), 287-303. https://doi.org/10.1007/s10869-018-9541-1

Madera, J. M., Hebl, M. R., \& Martin, R. C. (2009). Gender and letters of recommendation for academia: Agentic and communal differences. Journal of Applied Psychology, 94(6), 1591-1599. https://doi.org/10.1037/a0016539 
Mattern, K. D., \& Patterson, B. F. (2013). Test of slope and intercept bias in college admissions: A response to Aguinis, Culpepper, and Pierce (2010). Journal of Applied Psychology, 98(1), 134-147. https://doi.org/10.1037/a0030610

Melchers, K. G., Lienhardt, N., Von Aarburg, M., \& Kleinmann, M. (2011). Is more structure really better? A comparison of frame-of-reference training and descriptively anchored rating scales to improve interviewers' rating quality. Personnel Psychology, 64(1), 5387.

Messick, S. (1995). Validity of psychological assessment: Validation of inferences from persons' responses and performances as scientific inquiry into score meaning. American Psychologist, 50(9), 741-749. https://doi.org/10.1037/0003-066X.50.9.741

Milkman, K. L., Akinola, M., \& Chugh, D. (2015). What happens before? A field experiment exploring how pay and representation differentially shape bias on the pathway into organizations. Journal of Applied Psychology, 100(6), 1678-1712. https://doi.org/10.1037/ap10000022

Miller, A., Credé, M., \& Sotola, L. K. (2021). Should research experience be used for selection into graduate school: A discussion and meta-analytic synthesis of the available evidence. International Journal of Selection and Assessment, 29(1),19-28.

Miller, C. W., Zwickl, B. M., Posselt, J. R., Silvestrini, R. T., \& Hodapp, T. (2019). Typical physics Ph.D. admissions criteria limit access to underrepresented groups but fail to predict doctoral completion. Science Advances, 5(1), eaat7550. https://doi.org/10.1126/sciadv.aat7550

Miller, D., McCarthy, D., Fant, A., Li-Sauerwine, S., Ali, A., \& Kontrick, A. (2019). The Standardized Letter of Evaluation Narrative: Differences in Language Use by Gender. 
Western Journal of Emergency Medicine, 20(6), 948-956.

https://doi.org/10.5811/westjem.2019.9.44307

Moneta-Koehler, L., Brown, A. M., Petrie, K. A., Evans, B. J., \& Chalkley, R. (2017). The Limitations of the GRE in Predicting Success in Biomedical Graduate School. PLOS ONE, 12(1), e0166742. https://doi.org/10.1371/journal.pone.0166742

Morgan, W. B., Elder, K. B., \& King, E. B. (2013). The emergence and reduction of bias in letters of recommendation: Bias in letters of recommendation. Journal of Applied Social Psychology, 43(11), 2297-2306. https://doi.org/10.1111/jasp.12179

Murphy, M. J., Nelson, D. A., \& Cheap, T. L. (1981). Rated and Actual Performance of High School Students as a Function of Sex and Attractiveness. Psychological Reports, 48(1), 103-106. https://doi.org/10.2466/pr0.1981.48.1.103

Murphy, S. C., Klieger, D. M., Borneman, M. J., \& Kuncel, N. R. (2009). The Predictive Power of Personal Statements in Admissions: A Meta-Analysis and Cautionary Tale. College \& University, 84(4), 83-86.

National Center for Education Statistics. (2017, September). Digest of Education Statistics, 2017. https://nces.ed.gov/programs/digest/d17/tables/dt17_101.20.asp?referer=raceindicators

NCME.org. (2019). Statement on Admissions Test - NCME. https://www.ncme.org/publications/statements/new-item2

Nickerson, R. S. (1998). Confirmation Bias: A Ubiquitous Phenomenon in Many Guises: Review of General Psychology. https://journals.sagepub.com/doi/10.1037/1089-2680.2.2.175

Nicklin, J. M., \& Roch, S. G. (2008). Biases Influencing Recommendation Letter Contents: Physical Attractiveness and Gender1. Journal of Applied Social Psychology, 38(12), 3053-3074. https://doi.org/10.1111/j.1559-1816.2008.00425.x 
Niessen, A. S. M., \& Meijer, R. R. (2017). On the Use of Broadened Admission Criteria in Higher Education. Perspectives on Psychological Science, 12(3), 436-448. https://doi.org/10.1177/1745691616683050

Nisbett, R. E., \& Wilson, T. D. (1977). The halo effect: Evidence for unconscious alteration of judgments. Journal of Personality and Social Psychology, 35(4), 250-256. https://doi.org/10.1037/0022-3514.35.4.250

Norcross, J. C., Kohout, J. L., \& Wicherski, M. (2005a). Graduate Study in Psychology: 19712004. American Psychologist, 60(9), 959-975. https://doi.org/10.1037/0003066X.60.9.959

Norcross, J. C., Kohout, J. L., \& Wicherski, M. (2005b). Graduate Study in Psychology: 19712004. American Psychologist, 60(9), 959-975. https://doi.org/10.1037/0003066X.60.9.959

Nunnally, J. C., \& Bernstein, I. H. (1994). Psychometric Theory (3rd edition). McGraw-Hill.

O’Donnell, K., Botelho, J., Brown, J., González, G. M., \& Head, W. (2015). Undergraduate Research and Its Impact on Student Success for Underrepresented Students: Undergraduate Research and Its Impact. New Directions for Higher Education, 2015(169), 27-38. https://doi.org/10.1002/he.20120

Osman, N. Y., Schonhardt-Bailey, C., Walling, J. L., Katz, J. T., \& Alexander, E. K. (2015). Textual analysis of internal medicine residency personal statements: themes and gender differences. Medical Education, 49(1), 93-102. https://doi.org/10.1111/medu.12487

Outtz, J. L., \& Newman, D. A. (2010). A theory of adverse impact. In Adverse impact: Implications for organizational staffing and high stakes selection (pp. 53-94). Routledge/Taylor \& Francis Group. 
Pashak, T. J., Handal, P. J., \& Ubinger, M. (2012). Practicing What We Preach: How Are Admissions Decisions Made for Clinical Psychology Graduate Programs, and What Do Students Need to Know? Psychology, 03(01), 1-6. https://doi.org/10.4236/psych.2012.31001

Pennock-Román, M. (1993). Differences among racial and ethnic groups in mean scores on the GRE and SAT: Longitudinal comparisons (No. 86-09bP; pp. i-26). Educational Testing Service. http://doi.wiley.com/10.1002/j.2333-8504.1991.tb01380.x

Petersen, S. L., Erenrich, E. S., Levine, D. L., Vigoreaux, J., \& Gile, K. (2018). Multiinstitutional study of GRE scores as predictors of STEM PhD degree completion: GRE gets a low mark. PLOS ONE, 13(10), e0206570. https://doi.org/10.1371/journal.pone.0206570

Powers, D. E., \& Fowles, M. E. (1997). The personal statement as an indicator of writing skill: A cautionary note. Educational Assessment, 4(1), 75-87.

Pruitt, A. S., \& Isaac, P. D. (1985). Discrimination in Recruitment, Admission, and Retention of Minority Graduate Students. The Journal of Negro Education, 54(4), 526-536. JSTOR. https://doi.org/10.2307/2294713

Quillian, L., Pager, D., Hexel, O., \& Midtbøen, A. (2017). Meta-analysis of field experiments shows no change in racial discrimination in hiring over time | PNAS. PNAS Proceedings of the National Academy of Sciences of the United States of America, 114(41), 1087010875. https://doi.org/10.1073/pnas.1706255114

Roth, P. L., \& Bobko, P. (2000). College grade point average as a personnel selection device: Ethnic group differences and potential adverse impact. Journal of Applied Psychology, 85(3), 399-406. https://doi.org/10.1037/0021-9010.85.3.399 
Roth, P. L., Van Iddekinge, C. H., Huffcutt, A. I., Eidson Jr, C. E., \& Bobko, P. (2002). Corrections for range restriction in structured interview ethnic group differences: The values may be larger than researchers thought. Journal of Applied Psychology, 87(2), 369.

Russell, S. H., Hancock, M. P., \& McCullough, J. (2007). The pipeline: Benefits of Undergraduate Research Experiences. Science, 316(5824), 548-549. https://doi.org/10.1126/science. 1140384

Sacco, J. M., Scheu, C. R., Ryan, A. M., \& Schmitt, N. (2003). An investigation of race and sex similarity effects in interviews: A multilevel approach to relational demography. Journal of Applied Psychology, 88(5), 852.

Sackett, P. R., \& Kuncel, N. R. (2018). Eight myths about standardized admissions testing. In Measuring success: Testing, grades, and the future of college admissions (pp. 13-39). Johns Hopkins University Press.

Sackett, P. R., Kuncel, N. R., Beatty, A. S., Rigdon, J. L., Shen, W., \& Kiger, T. B. (2012). The Role of Socioeconomic Status in SAT-Grade Relationships and in College Admissions Decisions. Psychological Science, 23(9), 1000-1007. https://doi.org/10.1177/0956797612438732

Santelices, M. V., \& Wilson, M. (2012). On the Relationship Between Differential Item Functioning and Item Difficulty: An Issue of Methods? Item Response Theory Approach to Differential Item Functioning. Educational and Psychological Measurement, 72(1), 536. https://doi.org/10.1177/0013164411412943 
Scherbaum, C. A., \& Goldstein, H. W. (2008). Examining the Relationship Between Race-Based Differential Item Functioning and Item Difficulty. Educational and Psychological Measurement, 68(4), 537-553. https://doi.org/10.1177/0013164407310129

Schmader, T., Whitehead, J., \& Wysocki, V. H. (2007). A Linguistic Comparison of Letters of Recommendation for Male and Female Chemistry and Biochemistry Job Applicants. Sex Roles, 57(7-8), 509-514. https://doi.org/10.1007/s11199-007-9291-4

Schmidt, F. L., \& Hunter, J. E. (1998). The validity and utility of selection methods in personnel psychology: Practical and theoretical implications of 85 years of research findings. Psychological Bulletin, 124(2), 262.

Schwartz, B. (1982). Reinforcement-induced behavioral stereotypy: How not to teach people to discover rules. Journal of Experimental Psychology: General, 111(1), 23-59. https://doi.org/10.1037/0096-3445.111.1.23

Shaw, K., Holbrook, A., \& Bourke, S. (2013). Student experience of final-year undergraduate research projects: an exploration of 'research preparedness.' Studies in Higher Education, 38(5), 711-727. https://doi.org/10.1080/03075079.2011.592937

Sheard, M. (2009). Hardiness commitment, gender, and age differentiate university academic performance. British Journal of Educational Psychology, 79(1), 189-204. https://doi.org/10.1348/000709908X304406

Shewach, O. R., McNeal, K. D., Kuncel, N. R., \& Sackett, P. R. (2019). Bunny Hill or Black Diamond: Differences in Advanced Course-Taking in College as a Function of Cognitive Ability and High School GPA. Educational Measurement: Issues and Practice, 38(1), 25-35. https://doi.org/10.1111/emip.12212 
SIOP. (2018). Principles for the Validation and Use of Personnel Selection Procedures |Fifth Edition.

Sireci, S. G. (2016). On the validity of useless tests. Assessment in Education: Principles, Policy \& Practice, 23(2), 226-235. https://doi.org/10.1080/0969594X.2015.1072084

Snyder, J. A. (2020, July 6). Inequities in American society go well beyond testing (opinion)| Inside Higher Ed. https://www.insidehighered.com/admissions/views/2020/07/06/inequities-americansociety-go-well-beyond-testing-opinion

Sonnert, G., \& Fox, M. F. (2012). Women, Men, and Academic Performance in Science and Engineering: Journal of Higher Education, 83(1), 73-101.

Stasser, G., \& Titus, W. (1985). Pooling of unshared information in group decision making: Biased information sampling during discussion. Journal of Personality and Social Psychology, 48(6), 1467-1478. https://doi.org/10.1037/0022-3514.48.6.1467

Syverson, S. T., Franks, V. W., \& Hiss, W. C. (2018). Defining access: How test-optional works (pp. 1-85). National Association for College Admission Counseling.

Terenzini, P. T., Cabrera, A. F., \& Bernal, E. M. (n.d.). Swimming Against the Tide: The Poor in American Higher Education. Against the Tide, 62.

Tyson, C. (2014, June 16). STEM graduate programs place too much emphasis on GRE scores, physicists say. https://www.insidehighered.com/news/2014/06/16/stem-graduateprograms-place-too-much-emphasis-gre-scores-physicists-say

U.S. Equal Employment Opportunity Commission. (n.d.). Race/Color Discrimination. Retrieved August 18, 2020, from https://www.eeoc.gov/racecolor-discrimination 
Voyer, D., \& Voyer, S. D. (2014). Gender differences in scholastic achievement: A metaanalysis. Psychological Bulletin, 140(4), 1174-1204. https://doi.org/10.1037/a0036620

Walpole, M. (2003). Socioeconomic Status and College: How SES Affects College Experiences and Outcomes. The Review of Higher Education, 27(1), 45-73. https://doi.org/10.1353/rhe.2003.0044

Walpole, M., Burton, N. W., Kanyi, K., \& Jackenthal, A. (2002). Selecting successful graduate students: In-depth interviews with GRE users. ETS Research Report Series, 2002(1), i29. https://doi.org/10.1002/j.2333-8504.2002.tb01875.x

Weissman, M. B. (2020). Do GRE scores help predict getting a physics Ph.D.? A comment on a paper by Miller et al. Science Advances, 6(23), eaax3787. https://doi.org/10.1126/sciadv.aax3787

Wendler, C., \& Bridgeman, B. (2014). The Research Foundation for the GRE revised General Test: A Compendium of Studies. www.ets.org/gre/compendium

White, S. W., Xia, M., \& Edwards, G. (2020). Race, gender, and scholarly impact: Disparities for women and faculty of color in clinical psychology. Journal of Clinical Psychology. https://doi.org/10.1002/jclp.23029

Williams, L. A., \& Writer, C. S. (2019). More Than Half of Grad Student Survey Respondents Report Discrimination $\mid$ News | The Harvard Crimson. https://www.thecrimson.com/article/2019/11/7/gsc-half-discrimination/

Zajonc, R. B. (1968). Attitudinal effects of mere exposure. Journal of Personality and Social Psychology, 9(2, Pt.2), 1-27. https://doi.org/10.1037/h0025848 
Zhang, C., \& Kuncel, N. R. (2020). Moving Beyond the Brag Sheet: A Meta-Analysis of Biodata Measures Predicting Student Outcomes. Educational Measurement: Issues and Practice. https://doi.org/10.1111/emip.12313

Zieky, M. (2003). A DIF Primer. Princeton, NJ: Educational Testing Service. https://www.ets.org/s/praxis/pdf/dif_primer.pdf

Zwick, R. (2012). A Review of Ets Differential Item Functioning Assessment Procedures: Flagging Rules, Minimum Sample Size Requirements, and Criterion Refinement. ETS Research Report Series, 2012(1), i-30. https://doi.org/10.1002/j.23338504.2012.tb02290.x 
Table 1. Potential Sources of Variance in Tests Used in Graduate Admissions Decisions

\begin{tabular}{|c|c|c|c|c|c|c|c|c|}
\hline \multicolumn{3}{|c|}{ Sources of Variance in Test Scores } & \multirow{2}{*}{$\frac{\text { GRE }}{\mathrm{X}}$} & \multirow{2}{*}{$\frac{\text { UGPA }}{X}$} & \multirow{2}{*}{$\frac{\text { PS }}{X}$} & \multirow{2}{*}{$\frac{\mathbf{C V}}{\mathrm{X}}$} & \multirow{2}{*}{$\frac{\text { LOR }}{\mathrm{X}}$} & \multirow{2}{*}{$\frac{\text { Interview }}{\mathrm{X}}$} \\
\hline $\begin{array}{l}\text { Random } \\
\text { Variance }\end{array}$ & Error scores & & & & & & & \\
\hline \multirow{11}{*}{$\begin{array}{l}\text { Systematic } \\
\text { Variance }\end{array}$} & Content Biases & Construct Deficiency & $\mathrm{X}$ & $\mathrm{X}$ & $\mathrm{X}$ & $\mathrm{X}$ & $\mathrm{X}$ & $\mathrm{X}$ \\
\hline & $\begin{array}{l}\text { Sociocognitive } \\
\text { Biases }\end{array}$ & Mere exposure bias & & $X$ & & & $X$ & $\mathrm{X}$ \\
\hline & & Confirmation bias & & $\mathrm{X}$ & $\mathrm{X}$ & $\mathrm{X}$ & $\mathrm{X}$ & $\mathrm{X}$ \\
\hline & & Truth bias & & $\mathrm{X}$ & $\mathrm{X}$ & $\mathrm{X}$ & $X$ & $\mathrm{X}$ \\
\hline & & Similar-to-me bias & & $\mathrm{X}$ & $\mathrm{X}$ & $\mathrm{X}$ & $\mathrm{X}$ & $\mathrm{X}$ \\
\hline & & Attractiveness bias & & $\mathrm{X}$ & & $\mathrm{X}$ & $\mathrm{X}$ & $\mathrm{X}$ \\
\hline & & Anchoring bias & & $\mathrm{X}$ & $\mathrm{X}$ & $\mathrm{X}$ & $\mathrm{X}$ & $\mathrm{X}$ \\
\hline & Rater Biases & Halo bias & & $\mathrm{X}$ & $\mathrm{X}$ & $\mathrm{X}$ & $\mathrm{X}$ & $\mathrm{X}$ \\
\hline & & Central tendency bias & & $X$ & $X$ & $\mathrm{X}$ & $X$ & $X$ \\
\hline & & Leniency bias & & $X$ & $\mathrm{X}$ & $\mathrm{X}$ & $\mathrm{X}$ & $\mathrm{X}$ \\
\hline & & Severity bias & & $X$ & $\mathrm{X}$ & $\mathrm{X}$ & $X$ & $X$ \\
\hline
\end{tabular}

UGPA = Undergraduate GPA; PS = Personal Statement; LOR = Letters of Recommendation. 
Table 2. Summary of Literature on Validity, Bias, and Fairness Concerns Associated with Major Sources of Information in Graduate Admissions

\begin{tabular}{|c|c|c|c|}
\hline Predictor & Validity \& Reliability & Bias & $\begin{array}{c}\text { Fairness } \\
\end{array}$ \\
\hline UGPA & $\begin{array}{l}\text { Valid predictor of graduate GPA, } 1^{\text {st }} \\
\text { year graduate GPA, comprehensive } \\
\text { exam scores, and faculty-rated graduate } \\
\text { school performance }\end{array}$ & $\begin{array}{l}\text { - Attractive women may receive } \\
\text { higher grades than men of a } \\
\text { comparable achievement level }\end{array}$ & $\begin{array}{l}\text { - The relationship between SES and } \\
\text { UGPA is small, but significant } \\
\text { - Women tend to have higher } \\
\text { UGPAs than men } \\
\text { - Course choice, SES, and other } \\
\text { individual differences may impact } \\
\text { grades }\end{array}$ \\
\hline $\begin{array}{l}\text { Personal } \\
\text { Statements }\end{array}$ & $\begin{array}{l}\text { - Weak relationship with graduate GPA } \\
\text { and faculty performance ratings; no } \\
\text { incremental validity over standardized } \\
\text { test scores } \\
\text { - Poor indicator of writing ability } \\
\text { compared to standardized measures } \\
\text { - Lack of standardization results in lower } \\
\text { construct validity }\end{array}$ & $\begin{array}{l}\text { - Men writing personal statements } \\
\text { may include more agentic language } \\
\text { and self-promotion than women, } \\
\text { which may influence evaluations of } \\
\text { the statement }\end{array}$ & $\begin{array}{l}\text { - Students have unequal access to } \\
\text { mentors, faculty, or paid writing } \\
\text { services to help shape and edit } \\
\text { personal statements }\end{array}$ \\
\hline
\end{tabular}




\begin{tabular}{|c|c|c|c|}
\hline Resumes/CVs & $\begin{array}{l}\text { Research Experience } \\
\text { - Unclear how research experience } \\
\text { directly relates to graduate student } \\
\text { performance } \\
\text { - Based on self-reports, benefits include } \\
\text { interest in and motivation to attend } \\
\text { graduate school, research preparedness, } \\
\text { knowledge of the research process, and } \\
\text { preparedness to write a personal } \\
\text { statement } \\
\text { - Benefits of undergraduate research may } \\
\text { be particularly true for underrepresented } \\
\text { minorities } \\
\text { Undergraduate Institution Prestige } \\
\text { - Unclear whether the prestige of } \\
\text { undergraduate institutions relates } \\
\text { directly to graduate student success } \\
\text { - Prestige of undergraduate institution is } \\
\text { associated with future research } \\
\text { productivity and future earnings }\end{array}$ & $\begin{array}{l}\text { - Lack of research on how one's } \\
\text { Resume or CV may influence } \\
\text { sociocognitive bias }\end{array}$ & $\begin{array}{l}\text { - Existing barriers to research } \\
\text { involvement may not be equal } \\
\text { across all subgroups } \\
\text { - Men may be less likely to } \\
\text { participate in undergraduate } \\
\text { research } \\
\text { Prestigious undergraduate } \\
\text { institutions are expensive to } \\
\text { attend and difficult to be selected } \\
\text { into }\end{array}$ \\
\hline $\begin{array}{l}\text { Letters of } \\
\text { Recommendation }\end{array}$ & $\begin{array}{l}\text { - Small incremental validity over GRE } \\
\text { and UGPA for predicting Ph.D. } \\
\text { attainment and faculty performance } \\
\text { ratings } \\
\text { - Poor interrater reliability } \\
\text { - Lack of standardization results in lower } \\
\text { construct validity }\end{array}$ & $\begin{array}{l}\text { - Content and evaluation of letters } \\
\text { impacted by irrelevant factors (e.g., } \\
\text { gender, attractiveness, race) }\end{array}$ & $\begin{array}{l}\text { - Standardization and requiring } \\
\text { elaboration on ratings decrease } \\
\text { gender and race differences } \\
\text { - Developing a relationship with } \\
\text { letter writers requires time and } \\
\text { effort; barriers may be greater for } \\
\text { some subgroups }\end{array}$ \\
\hline $\begin{array}{l}\text { Interviews } \\
\text { (Unstructured) }\end{array}$ & $\begin{array}{l}\text { - Lack of research on graduate admissions } \\
\text { interviews, but research on employment } \\
\text { interviews may be relevant } \\
\text { - Increasing interview structure (e.g., } \\
\text { standardization) increases validity and } \\
\text { reliability compared to unstructured } \\
\text { interviews }\end{array}$ & $\begin{array}{l}\text { - A higher body mass index is related } \\
\text { to fewer post-interview offers for } \\
\text { graduate school } \\
\text { - Explicit or implicit biases influence } \\
\text { interview scores } \\
\text { - Structuring interviews reduce the } \\
\text { impact of bias }\end{array}$ & $\begin{array}{l}\text { - Attending graduate student } \\
\text { interviews is expensive, may } \\
\text { require students to take off work, } \\
\text { etc. }\end{array}$ \\
\hline
\end{tabular}


Rethinking Graduate Admissions 65

\begin{tabular}{|c|c|c|c|}
\hline & $\begin{array}{l}\text { - Predictive value of interviews may still } \\
\text { be impacted by self-presentation and } \\
\text { poor construct validity }\end{array}$ & $\begin{array}{l}\text { - Despite the positive impact of } \\
\text { structuring interviews, interviewers } \\
\text { often resist structure opening the } \\
\text { door for bias }\end{array}$ & \\
\hline GRE & $\begin{array}{l}\text { Valid predictor of graduate GPA, } 1^{\text {st }} \\
\text { year graduate GPA, comprehensive } \\
\text { exam scores, and faculty-rated graduate } \\
\text { school performance }\end{array}$ & $\begin{array}{l}\text { - Item difficulty predicts DIF on GRE } \\
\text { and SAT items for Black and White } \\
\text { test takers } \\
\text { - For the SAT-UGPA relationship, } \\
\text { find differential prediction between } \\
\text { Black and White students } \\
\text { (overpredicts UGPA for Black } \\
\text { students) and between men and } \\
\text { women (underpredicts UGPA for } \\
\text { female students) }\end{array}$ & $\begin{array}{l}\text { - Racial subgroup differences in } \\
\text { GRE-V and GRE-Q scores; these } \\
\text { differences remain fairly stable in } \\
\text { a longitudinal analysis examining } \\
\text { students who took both the SAT } \\
\text { and GRE } \\
\text { - Taking the GRE is costly and } \\
\text { paying for a preparatory class is } \\
\text { even more expensive }\end{array}$ \\
\hline
\end{tabular}


Table 3. Meta-Analytic Effect Sizes of Admission Measures

\begin{tabular}{|c|c|c|c|c|c|c|c|c|}
\hline & GGPA & $\begin{array}{l}1^{\text {st }} \text { year } \\
\text { GGPA }\end{array}$ & $\begin{array}{l}\text { Comp. } \\
\text { Exam } \\
\text { Score }\end{array}$ & $\begin{array}{l}\text { Faculty } \\
\text { Ratings }\end{array}$ & $\begin{array}{c}\text { Degree } \\
\text { Attainment }\end{array}$ & $\begin{array}{c}\text { Time to } \\
\text { Completion }\end{array}$ & $\begin{array}{c}\text { Research } \\
\text { Productivity }\end{array}$ & $\begin{array}{c}\text { Citation } \\
\text { Count }\end{array}$ \\
\hline GRE-V $^{1}$ & $.23(.34)$ & $.24(.34)$ & $.34(.44)$ & $.23(.42)$ & $.14(.18)$ & $.21(.28)$ & $.07(.09)$ & $.13(.17)$ \\
\hline GRE-Q $^{1}$ & $.21(.32)$ & $.24(.38)$ & $.19(.26)$ & $.25(.47)$ & $.14(.20)$ & $-.08(-.12)$ & $.08(.11)$ & $.17(.23)$ \\
\hline GRE-A $^{1}$ & $.24(.36)$ & $.24(.36)$ & & $.23(.35)$ & $.08(.11)$ & & & \\
\hline $\begin{array}{l}\text { GRE- } \\
\text { Subject }^{1}\end{array}$ & $.31(.41)$ & $.34(.45)$ & $.43(.51)$ & $.30(.50)$ & $.32(.39)$ & $.02(.02)$ & $.17(.21)$ & $.20(.24)$ \\
\hline $\mathrm{UGPA}^{1}$ & $.28(.30)$ & $.30(.33)$ & $.12(.12)$ & $.25(.35)$ & $.12(.12)$ & $-.08(-.08)$ & & \\
\hline $\mathrm{PS}^{2}$ & .13 & & & .09 & & & & \\
\hline $\mathrm{LOR}^{3}$ & .13 & & & .25 & .19 & & .10 & \\
\hline Res $\operatorname{Exp}^{4}$ & .01 & & & & .05 & & .11 & \\
\hline
\end{tabular}

Note. Values in parantheses are mean meta-analytic effect size estimates following corrections for range restriction and measurement error. ${ }^{1}$ Kuncel et al (2001); ${ }^{2}$ Murphy et al (2009); ${ }^{3}$ Kuncel et al (2014); ${ }^{4}$ Miller et al (2021). 


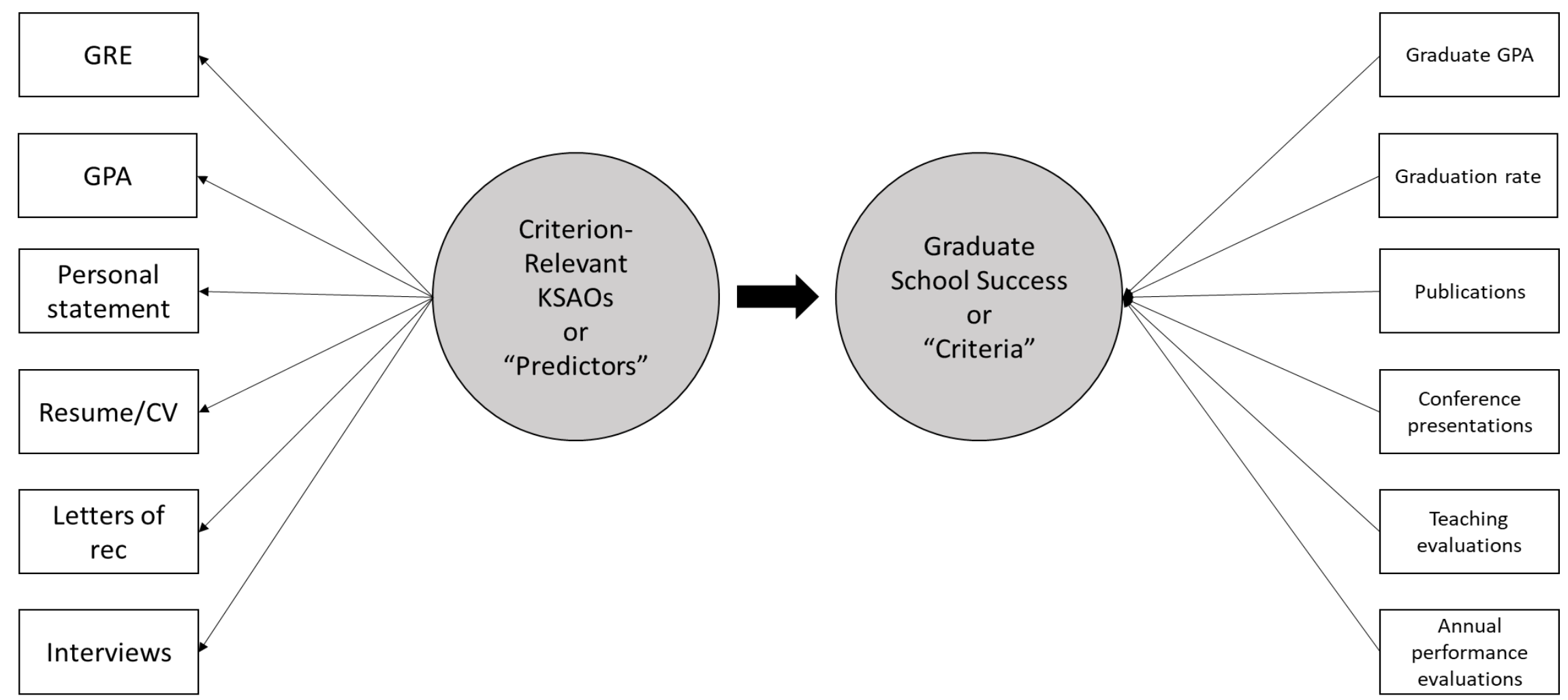

Figure 1. Measures of Graduate School Predictors and Criteria

[KSAOs refer to knowledge, skills, abilities, and other characteristics.] 


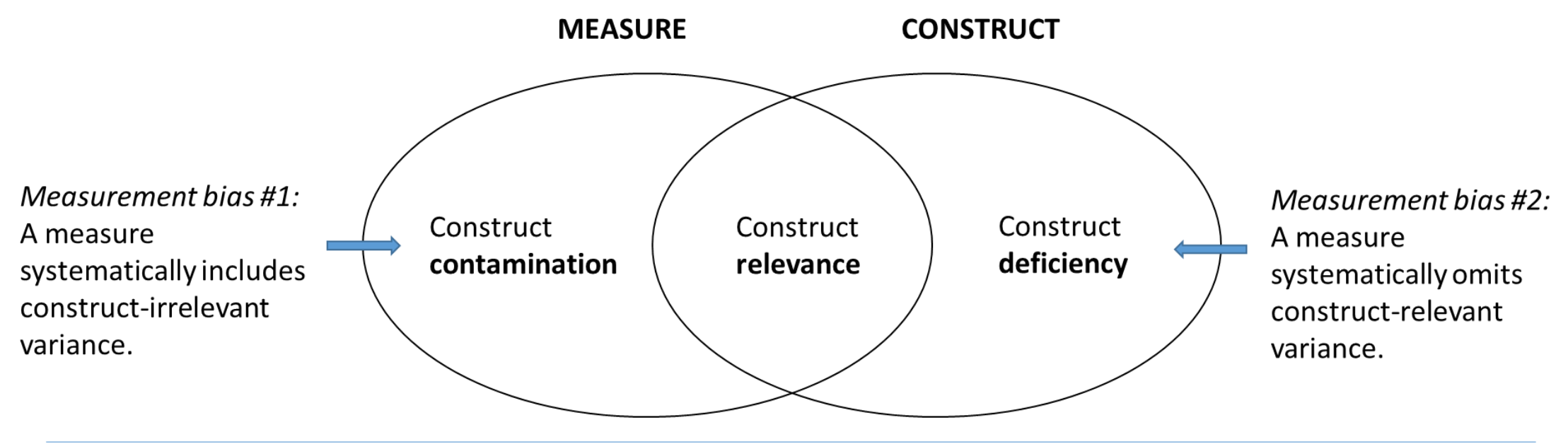

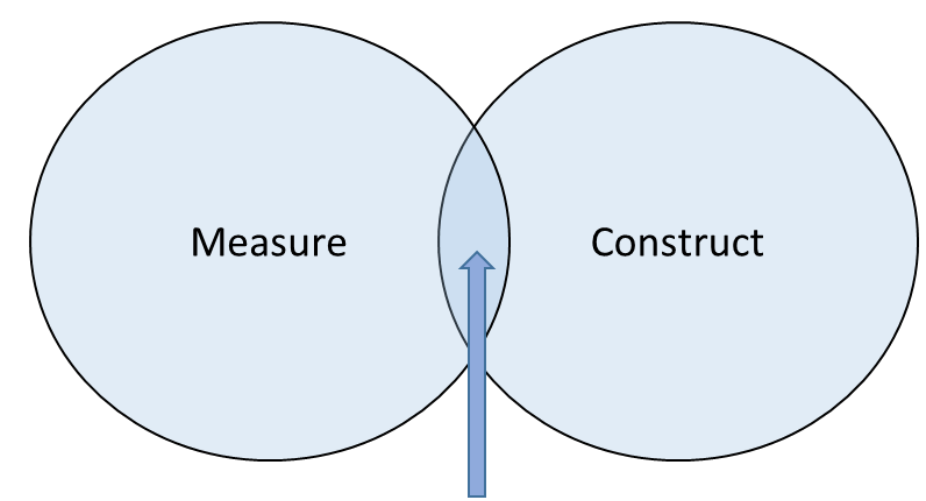

Measure's construct relevance is low

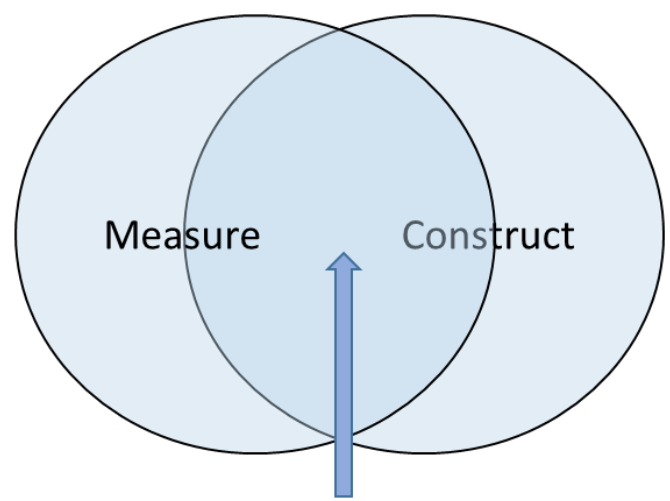

Measure's construct relevance is high

Figure 2. An Illustration of Measurement Biases and Construct Relevance, Contamination, and Deficiency 


\section{Appendix A: A Flow Diagram of the Literature Search Process}

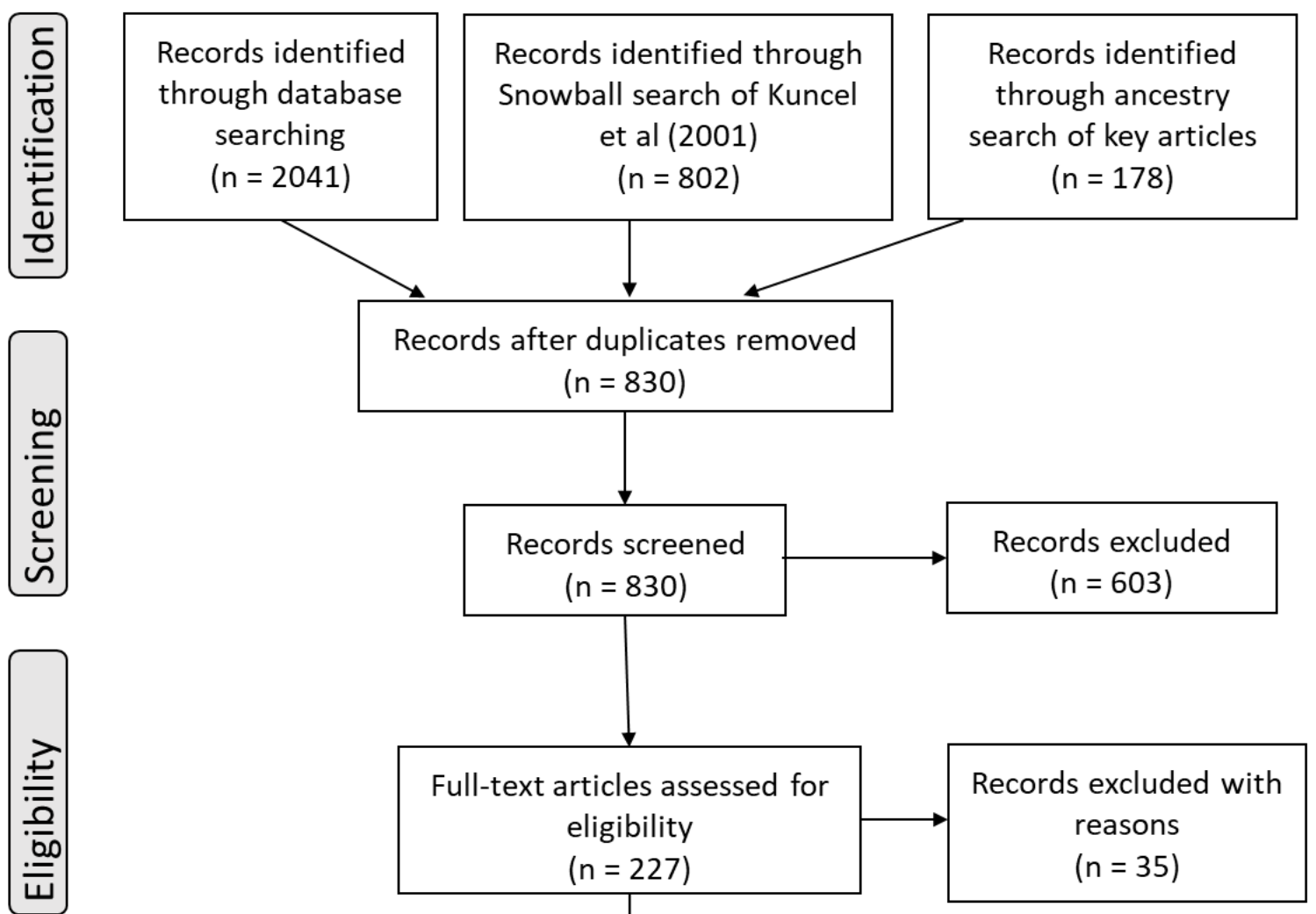

Studies included in qualitative synthesis

$$
\text { ( } n=192 \text { ) }
$$


Rethinking Graduate Admissions 70

\section{Appendix B: More discussions on GRE's validity and bias issues}

\section{Contrarian views on GRE's validity}

Although the conclusions based on meta-analytic reviews suggest that, on average, GRE scores are predictive of relevant criteria, it is always possible to find a study where the results were not so compelling. For example, Hall et al. (2017) collected data on $N=280$ students enrolled in a Ph.D. program in biomedical sciences at the University of North Carolina. Using GRE scores, the authors sought to predict student productivity. They concluded, “...the most commonly used standardized test (the general GRE) is a particularly ineffective predictive tool, but that qualitative assessments by previous mentors are more likely to identify students who will succeed in biomedical graduate research" (p. 1). A closer examination of this study raises some concerns about the validity of this inference linking GRE scores to graduate school performance. First, a perusal of the descriptive statistics from their sample suggests data likely violated assumptions of normality, and that range restriction may have plagued criteria and predictors (e.g., first-authored publications with their graduate advisor, $M=1.45, S D=1.40$; GRE Quantitative percentile scores, $M=72.48, S D=17.47$ ). Furthermore, one of the key criterion variables was recoded from its continuous form (e.g., number of publications with their primary advisor) into a trichtomous, three-level variable. Although the article claimed that it was going to test for "correlations between application components and graduate student productivity" (p. 4), we were unable to locate a single correlation coefficient in the manuscript. Instead, the authors relied on their visual inspection of bivariate scatterplots to infer the lack of significant relationships.

Similarly, Moneta-Koehler et al. (2017) concluded that "GRE scores were found to be moderate predictors of first-semester grades, and weak to moderate predictors of graduate GPA and some elements of faculty evaluation" (p. 1). Again, a closer examination of this study reveals several aspects of their study that raise questions about the validity of this inference. First, they had data on a single sample of graduate students from Vanderbilt University's interdisciplinary graduate program (IGP) that focuses on biomedical research. Data were initially collected on a sample of $N=683$ students; however, due to missing data, the sample sizes varied considerably depending on the variable of interest - including GREs $(N=495)$, first-authored publications $(N=271)$, overall graduate GPA $(N=492)$, time to dissertation defense $(N=318)$, and faculty evaluations $(N=210)$. In addition to missing data (some of which was likely not missing completely at random), scores on predictors (e.g., GRE-Q; $M=693.35, S D=67.34$ ) and criteria appeared to be restricted (e.g., 1st-semester grades; $M=79.73, S D=0.90$ ). Finally, the data also appeared to violate normality assumptions (e.g., first-authored publication count; $M=1.79, S D=1.10$ ). Additionally, a table of correlations was also notably absent from their article, and it is unclear from the multiple regression analysis, where the GRE was shown as the only predictor, what the (adjusted) $R^{2}$ of .28 means.

Most recently, in the context of physics Ph.D. program admissions, C. Miller and colleagues (C. W. Miller et al., 2019) published an article concluding that GRE has little validity in predicting doctoral completion. This study (and the authors' overall conclusion from the presented data) has since been criticized by Weissman (2020), who aptly pointed out a number of methodological issues derived from questionable and/or inappropriate analytic strategies adopted in the Miller et 
al.'s study - namely, “collider-like stratification bias, variance inflation by collinearity and range restriction, omission of parts of a needed correlation matrix, a peculiar choice of null hypothesis on subsamples, blurring the distinction between failure to reject a null and accepting a null, and an unusual procedure that inflates the confidence intervals in a figure" (p. 1).

\section{Efforts made by ETS to identify and address measurement bias in the GRE}

For roughly the last 40 years, ETS has systematically studied the items comprising standardized tests, such as the GRE, for evidence of measurement bias/DIF. Over the course of those four decades, ETS has publicly released a number of technical reports summarizing the protocols used to identify and remove items demonstrating problematic DIF and explains how the organization uses this information to minimize bias in their tests (Wendler \& Bridgeman, 2014). For example, Zieky (2003) explained:

Years of collected data on questions suggest that certain topics and contexts tend to be associated with higher than chance occurrences of [problematic DIF]. When sufficient evidence exists, test developers are told not to write such questions unless they are required for the measurement of some particular subject (p.4).

Thus, in instances when the item content is irrelevant to the focal construct, items demonstrating DIF are removed from ETS assessments. However, in instances where the item content is essential to the underlying focal construct, an item demonstrating DIF could be retained (see also de Ayala, 2009 for discussion of how to evaluate items flagged as having significant DIF as either biased or unbiased). As an example of the latter situation, Zieky (2003) noted, “....women taking a licensing test for nurses may find a question concerning breast cancer easier than do a matched sample of men. If the question measures information that all nurses ought to know, the question would be fair in spite of the difference. The same question, however, might be considered unfair on a test of general knowledge taken by people without specialized training in nursing." (p. 3). In addition, to using the results of these DIF analyses to inform test construction decisions, ETS has examined and revised its DIF detection protocols (e.g., Zwick, 2012) and has published a number of technical reports, chapters, and peer-reviewed articles focused on improving tests such as the GRE. 


\section{Appendix C: Guidelines for Standardizing Graduate Admission Procedures}

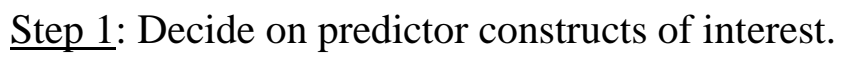

- Develop a list of KSAOs that are important for your graduate program. Doing so allows each graduate program to have a set of predictor constructs that are important for success (i.e., criteria). Such decisions can be informed by the scientific literature, as well as inputs from the faculty and others involved in the graduate school training. This is called a 'personoriented job analysis' technique in the I-O literature; see the Principles (SIOP, 2018) for more detailed information.

- One important factor to consider in determining the importance of each predictor construct is the developability or malleability of each predictor construct. Compared to employee selection contexts in a typical business setting, judgment and decision-making in school admissions should take into account the possibilities (and imperatives) of individuals' development and growth over time. Also important to note is the fact that individuals' growth is not only a function of the person's responsibility but also facilitated (or stymied) by various situational and environmental factors (e.g., supportive mentorship and quality of the training received in the program).

Step 2: Link the predictor constructs to the existing assessment methods in an explicit/formal, quantitative, and standardized manner.

- For each assessment method (e.g., interview), create a 'grading rubric' that is ideally applicable to all applicants.

○ For example, if 'advanced quantitative skills' is on the key predictor list, then come up with a list of specific keywords that can be coded under that umbrella (e.g., "R," "SPSS," "multivariate"). You may consider differential weights given to different keywords (e.g., proficiency in R counts more than beginner-level exposure to SPSS).

- Create a construct-by-measure matrix that specifies how each construct is captured in which measures; below is an illustrative (hypothetical) example. Such a matrix may be further expanded into sub-dimensions under each construct; it can also specify the level of content relevance for each measure (see Figure 2) for more nuanced assessments and information integration for ultimate selection decisions.

\begin{tabular}{|l|c|c|c|c|c|c|}
\hline & $\begin{array}{c}\text { Knowledge in } \\
\text { I-O } \\
\text { psychology } \\
\text { literature }\end{array}$ & $\begin{array}{c}\text { Motivation } \\
\text { for scientific } \\
\text { research }\end{array}$ & $\begin{array}{c}\text { Advanced } \\
\text { quantitative } \\
\text { skills }\end{array}$ & Writing skills & $\begin{array}{c}\text { Interpersonal } \\
\text { communication }\end{array}$ & $\begin{array}{c}\text { Critical } \\
\text { thinking } \\
\text { ability }\end{array}$ \\
\hline $\begin{array}{l}\text { GRE- } \\
\text { General Test }\end{array}$ & $\mathrm{X}$ & $\mathrm{X}$ & $\mathrm{X}$ & $\mathrm{X}$ & & $\mathrm{X}$ \\
\hline GPA & $\mathrm{X}$ & $\mathrm{X}$ & $\mathrm{X}$ & $\mathrm{X}$ & & $\mathrm{X}$ \\
\hline $\begin{array}{l}\text { Personal } \\
\text { statement }\end{array}$ & $\mathrm{X}$ & $\mathrm{X}$ & $\mathrm{X}$ & $\mathrm{X}$ & & $\mathrm{X}$ \\
\hline Letters of rec & $\mathrm{X}$ & $\mathrm{X}$ & $\mathrm{X}$ & $\mathrm{X}$ & & $\mathrm{X}$ \\
\hline Resume/CV & & & & & $\mathrm{X}$ & $\mathrm{X}$ \\
\hline Interviews & & & & & \\
\hline
\end{tabular}


- Conduct a frame-of-reference training. This is a common practice in I-O when utilizing human raters to minimize sociocognitive and rater biases and consequently minimize measurement biases. See the Guidelines and Ethical Considerations for Assessment Center Operations (International Taskforce on Assessment Center Guidelines, 2015) for examples of assessment center assessor training protocols.

Alternative Step 2: Alternatively, graduate programs that wish to completely overhaul their admissions system may consider expanding the number of currently examined predictors (e.g., Niessen \& Meijer, 2017; Zhang \& Kuncel, 2020) or developing a new set of methods for measuring the predictor constructs identified from Step 1. Doing so requires substantial efforts that may take up to several years (see Standards and Principles for more detailed guidance).

Step 3: Decide how all information gathered from the entire admission process will be systematically recorded, assessed, and integrated into a final decision.

- Following best-practice recommendations in the employment selection context (SIOP, 2018), careful and consistent notetaking practices are recommended throughout the process.

- Assessment results are best recorded using a standardized numeric scale.

- Cut scores may be used for multiple-hurdle selection decisions. For example, the admission committee may collectively decide on the minimum required undergraduate GPA and GRE scores, which will then be used to identify candidates to be examined more closely (e.g., via interviews).

- Implementing a mechanical integration method is recommended (Kuncel et al., 2013). Differential weights given to individual measures (' $\mathrm{X}$ ' variables in the regression equation) can be used. Such decisions are ideally openly discussed and explicitly agreed upon by all members of the graduate admission committee prior to the review of the application materials so that personal/subjective preferences for a particular candidate do not affect the way differential weights are determined (i.e., avoiding the possibility of manipulating the formula to sway the final selection results).

- Relying on clinical (unstandardized) integration and decision-making methods can have detrimental effects (Dawes et al., 1989; Grove et al., 2000; Highhouse \& Kostek, 2013; Kuncel et al., 2013), as they allow room for subjectivity and a whole host of sociocognitive biases that undermine both validity and bias/fairness of the decisions. Therefore, we further emphasize that, although graduate admission decisions are not likely to be made in a purely algorithmic manner (e.g., each individual faculty advisor ultimately decides whom they would like to admit), incorporating more structure and standardization to the assessment and integration/decision process is highly recommended (e.g., providing the faculty advisor with detailed information about each candidate's strengths and weakness based on a clearly defined grading rubric that links key predictor attributes to measurement data gathered throughout the evaluation process).

Step 4: Integrate constructs of interest into graduate student development and evaluation. For example, if knowledge of I-O psychology literature is a critical factor identified for success in an I-O psychology program, how do classes develop this attribute? Do evaluations measure knowledge of I-O psychology? 
Step 5: Use such evaluations as well as other predictor measures identified to evaluate the selection system over time (Binning \& Barrett, 1989).

In Steps 4 and 5, be aware of false negatives (Einhorn \& Hogarth, 1978) - i.e., those who were not selected into the program but could have been successful if they had been admitted. Again, this is a critical area of practical consideration and further scholarly discussion in higher education, as graduate programs are designed to foster the growth of success factors (i.e., attributes leading to success). Those who are selected into a high-quality graduate program will be given opportunities to develop the attributes that contribute to their success (i.e., predictor constructs), which will then lead to their ultimate success. 